\title{
S3 Guideline: Sedation for gastrointestinal endoscopy 2008
}

Authors

Institutions
A. Riphaus, T. Wehrmann, B. Weber, J. Arnold, U. Beilenhoff, H. Bitter, S. von Delius, D. Domagk, A. F. Ehlers, S. Faiss, D. Hartmann, W. Heinrichs, M.-L. Hermans, C. Hofmann, S. In der Smitten, M. Jung, G. Kähler, M. Kraus, J. Martin, A. Meining, J. Radke, T. Rösch, H. Seifert, A. Sieg, B. Wigginghaus, I. Kopp

The affiliations are listed in Table 1 of this document.
Bibliography

Dol $10.1055 / \mathrm{s}-0029-1215035$

Published online

14 August 2009

Endoscopy 2009; 41:

787-815 @ Georg Thieme

Verlag KG Stuttgart · New York ISSN 0013-726X

\section{Corresponding authors}

A. Riphaus, MD

Ruhr-Universität Bochum,

Medizinische Universitätsklinik, Knappschaftskrankenhaus

In der Schornau 23-25

44892 Bochum

Germany

Fax: +49-234-299-3409

ariphaus@web.de

\section{T. Wehrmann, MD}

Fachbereich Gastroenterologie Deutsche Klinik für Diagnostik

Aukammallee 33

65193 Wiesbaden

Germany

Fax: +49-611-577460

till.wehrmann@

dkd-wiesbaden.de

\section{Contents \\ $\nabla$}

Introduction

1 Indications/goals/known risks/patients/quality goals

1.1 Recommendation on sedation choices

1.2 Recommendation on indications for sedation

1.3 Recommendation on examination quality

1.4 Recommendation on risk assessment and structure quality

1.4.1 General

1.5 Recommendation on anesthesia/intubation

1.6 Recommendation on protective intubation

1.7 Recommendation on patient positioning

2 Sedatives/analgesics/drugs acting on the autonomic nervous system/combination therapy/methods of administration

2.1 Acceptance by the patient and the endoscopist

2.1.1 Patient acceptance/satisfaction

2.1.2 Endoscopist satisfaction

2.2 Monotherapies

2.2.1 Propofol

2.2.2 Benzodiazepines

2.2.3 Propofol versus midazolam

2.2.4 Other drugs as monotherapeutics

2.3 Combination therapies

2.3.1 General

2.3.2 Specific combinations

2.3.3 Side effects of combination therapy

2.3.4 Monitoring/structure quality

2.4 Effect of co-morbidity

2.4.1 General

2.4.2 High-risk patients

2.4.3 Substance type

2.5 Music during endoscopy

3 Structure quality: personal/personnel/equipment requirements

Introduction

3.1 Personal requirements

3.2 Education and training courses

3.3 Personnel requirements

3.3.1 Education requirements

3.3.2 Sedation monitoring

3.3.3 Carrying out the sedation

3.3.4 Monitoring after the endoscopic procedure

3.4 Facilities requirements

3.5 Equipment

3.5.1 Clinical monitoring/standard monitoring
3.5.2 Extended monitoring

4 Informed consent/prerequisites for performance of sedation/preservation of vital functions/clinical monitoring/ emergency management

4.1 Informed consent of the patient

4.1.1 General and legal aspects

4.1.2 Informing person

4.1.3 Informed consent procedure

4.1.4 Content of the patient information interview

4.1.5 Safety information (patient do's and don't's after endoscopic sedation)

4.2 Requirements for carrying out sedation

4.3 Protection of vital functions

4.4 Management of sedation-related emergencies

4.4.1 Hypoxemia

4.4.2 Cardiac arrhythmias

4.4.3 Arterial hypotension

4.4.4 Myocardial ischemia

4.4.5 Rare events during sedation

5 Quality goals: internal quality assurance/discharge criteria/fitness for road traffic/ability to work/

documentation/benchmarking

5.1 Internal quality assurance

5.2 Discharge criteria

5.2.1 Patient instructions

5.2.2 Minimum criteria for discharge

5.2.3 Use of score systems for discharge

5.3 Fitness for road traffic

5.4 Documentation

5.4.1 General

5.4.2 Inability to work

5.5 Benchmarking 
Table 1 Guideline group: professional associations and organizations involved.

\section{Professional society/task force/organization}

Endoscopy Section on behalf of the German Society for Digestive and Metabolic Diseases (Deutsche Gesellschaft für Verdauungs- und Stoffwechselkrankheiten, DGVS)

German Society for Anesthesiology and Intensive Care Medicine (Deutsche Gesellschaft für Anästhesie und Intensivmedizin, DGAI)

German Association of Gastroenterologists in Private Practice (Berufsverband Niedergelassener Gastroenterologen, bng) Surgical Task Force for Endoscopy and Sonography of the German Society for General and Visceral Surgery (Chirurgische Arbeitsgemeinschaft für Endoskopie und Sonographie, CAES, der Deutschen Gesellschaft für Allgemein- und Viszeralchirurgie, DGAV) Society for Legislation and Politics in Health Care (Gesellschaft für Recht und Politik im Gesundheitswesen, GRPG)

German Society for Endoscopy Assisting Personnel (Deutsche Gesellschaft für Endoskopieassistenzpersonal, DEGEA)

German Crohn's Disease/Ulcerative Colitis Association (Deutsche Morbus

Crohn/Colitis ulcerosa Vereinigung, DCCV)

\section{Authors entitled to vote}

Prof. Dr. Joachim Arnold, II. Medizinische Klinik, Diakoniekrankenhaus Rothenburg (Wümme), Dr. Stefan von Delius, II. Medizinische Klinik und Poliklinik des Klinikum rechts der Isar Der Technischen Universität München, PD Dr. Dirk Domagk, Medizinische Klinik und Poliklinik B Universitätsklinikum Münster, PD. Dr. Siegbert Faiss, III. Medizinische Abteilung Asklepios Klinik Barmbek, Hamburg, PD Dirk Hartmann, Medizinische Klinik C Klinikum Ludwigshafen, Dr. Christopher Hofmann, Klinik für Innere Medizin und Gastroenterologie, Katholisches Klinikum Mainz, Prof. Dr. Michael Jung, Klinik für Innere Medizin und Gastroenterologie, Katholisches Klinikum Mainz, Prof. Dr. Alexander Meining, II. Medizinische Klinik und Poliklinik des Klinikum rechts der Isar Der Technischen Universität München, Dr. Andrea Riphaus, Medizinische Universitätsklinik, Knappschaftskrankenhaus, Ruhr-Universität Bochum, Prof. Dr. Thomas Rösch, Klinik und Poliklinik für Interdisziplinäre Endoskopie, Universitätsklinik Hamburg-Eppendorf, PD Dr. Hans Seifert, Klinik für Innere Medizin I Klinikum Oldenburg GmbH, Prof. Dr. Andreas Sieg, Praxis für Gastroenterologie Heidelberg, Prof. Dr. Till Wehrmann, FB Gastroenterologie, Stiftung Deutsche Klinik für Diagnostik $\mathrm{GmbH}$

Prof. Dr. Wolfgang Heinrichs, Klinik für Anästhesiologie Universitätskliniken Mainz, PD Dr. Jörg Martin, Klinik für Anästhesiologie Klinik am Eichert, Kliniken des Landkreises Göppingen GmbH, Prof. Dr. Joachim Radke, Universitätsklinik für Anästhesiologie und operative Intensivmedizin, Universitätsklinikum der Martin-Luther-Universität Halle-Wittenberg

Dr. Marie-Luise Hermans, Praxis für Gastroenterologie Euskirchen, Dr. Bernd Wigginghaus, Praxis für Gastroenterologie Osnabrück

Dr. Martin Kraus, Klinik für Chirurgie, Universitätsklinikum Lübeck, PD Dr. Georg Kähler

Sektion Chirurgische Endoskopie, Universitätsklinik Mannheim

Dr. Horst Bitter, Prof. Dr. Dr. Alexander Friedrich Ehlers, Rechtsanwaltssocietät Ehlers, Ehlers \& Partner

Ulrike Beilenhoff, DEGEA, UIm

Dr. Susanne In der Smitten, Deutsche Morbus Crohn/Colitis ulcerosa Vereinigung DCCV-Bundesgeschäftsstelle Leverkusen
As we have done before for the guidelines of the French SFED, we are publishing an English translation of the recent German guideline on sedation. We will follow this practice occasionally with national guidelines of high quality. They will form the basis for an expansion of the ESGE guidelines which - under the direction of our board member Jean Marc Dumonceau - we will publish in the core part of our journal. Unified European guidelines are an integral part of the drive to bring our different national approaches in the field of endoscopy together.

\section{Guido Costamagna}

President, ESGE

Thomas Rösch

Editor-in-Chief, Endoscopy

This guideline is published by the Endoscopy Section of the German Society for Digestive and Metabolic Diseases (Deutsche Gesellschaft für Verdauungs- und Stoffwechselerkrankungen, DGVS), which also has ultimate responsibility for them. Co-publishers are the professional associations and organizations that participated in the preparation of this guideline:

- German Association of Gastroenterologists in Private Practice (Bundesverband Niedergelassener Gastroenterologen Deuschlands, bng)
- Surgical Work Group for Endoscopy and Sonography of the German Society for General and Visceral Surgery (Chirurgischen Arbeitsgemeinschaft für Endoskopie und Sonographie der Deutschen Gesellschaft für Allgemein- und Viszeralchirurgie, DGAV)

- German Crohn's Disease/Ulcerative Colitis Association (Deutsche Morbus Crohn/Colitis ulcerosa Vereinigung, DCCV)

- German Society for Endoscopy Assisting Personnel (Deutsche Gesellschaft für Endoskopie-Assistenzpersonal, DEGEA)

- German Society for Anesthesia and Intensive Care Medicine (Deutsche Gesellschaft für Anästhesie und Intensivmedizin, DGAI)

- Society for Legislation and Politics in Health Care (Gesellschaft für Recht und Politik im Gesundheitswesen, GPRG) under the direction of T. Wehrmann, A. Riphaus, and I. Kopp.

\section{Introduction}

$\nabla$

Background, rationale, and goals of the guideline

In the past few years, interest in sedation in gastrointestinal endoscopy has increased. It is currently the subject of much debate, some of it very lively.

One major issue is the exact indication for sedation. Premedication is not necessary for all gastroenterological endoscopic interventions. Whether it is required depends on the nature of exam- 
ination, its duration, its complexity, its invasiveness, and on the individual patient's characteristics. However, premedication can make the examination more comfortable for both the patient and the examining physician. Often it is premedication that makes a successful and low-risk examination possible. This is especially true for complex therapeutic interventions.

In the mid 1990s, sedation was much less often employed for endoscopic examinations in Germany and Switzerland than in the United States and the United Kingdom: in the USA and the UK patient sedation took place in up to $88 \%$ of endoscopic examinations $[1,2]$, whereas in Germany and Switzerland the figure was about $9 \%[3,4]$. However, a recent "nationwide evaluation of sedation in gastrointestinal endoscopy in Germany" has shown a pronounced increase in the frequency of sedation for endoscopic intervention, which is now given in up to $88 \%$ of cases [5]. This is most likely due to the increase in interventional procedures, and also to patient preferences, e.g., during colon carcinoma screening.

Apart from the long-familiar and most common form of sedation using sedatives such as benzodiazepines - sometimes in combination with opioids - the short-acting hypnotic propofol, with its plasma half-life of 7-8 minutes, is increasingly coming into use. The advantage of propofol is that the recovery time is significantly shorter while patient tolerance is equal [6,7]. In addition, the patient recovers psychomotor capacity much more quickly, as shown using a driving simulator [8]. However, now and again different sedation depths may be crossed with a single dose of this drug, which can cause sedation to be deeper than intended. Furthermore, unlike for midazolam, no antagonist exists for propofol. The recommendation of the various professional associations is still that the patient should not use the roads (even as a passenger) for 24 hours after the intervention [9-11]. There is a lack of evidence to support this advice, and it may not reflect the more rapid recovery that is achieved after the administration of shorter-acting agents.

A current issue of debate is propofol sedation by nurses ("nurseadministered propofol sedation" or NAPS). The increasing costs incurred under the Diagnosis-Related Group (DRG) settlement conditions and hence the requirement to reduce the costs of individual examinations have triggered a discussion of whether the sedation can be carried out by trained nurses. Currently more than 200000 patients have undergone NAPS without the need for endotracheal intubation [12-18]. However, these were mostly healthy patients undergoing diagnostic examinations, and the propofol dosages used were on the low side. Thus, uncritical acceptance of this concept is not recommended. On the contrary, in Germany we have yet to define conditions that would make this procedure safe for patients (e.g., appropriate training in sedation and emergency management).

The S3 guideline "Sedation for Gastrointestinal Endoscopy" presented here by various medical professional associations (among them gastroenterologists, surgeons, and anesthetists) and patient self-help groups is intended to define the structural requirements needed for sedation in gastrointestinal endoscopy and the control of any sedation-related complications, including legal aspects.

The main rationale for the preparation of the guideline is the increasing role of sedation in gastrointestinal endoscopy. In addition to optimal patient preparation, which includes not only adequate information about the sedation, but also risk stratification of the individual patient, an overview will be given of the most common current sedatives and analgesics (with particular atten- tion to the increasingly used short-acting substances) and their efficacy and side-effect profiles.

Drug therapies with different substances will be compared in terms of their efficacy and effectiveness during the examination and their risk profiles (particularly in relation to individual risk groups). Patient preferences, quality management of sedation using appropriate monitoring, and incident management will be covered.

The goals of the S3 guideline "Sedation for Gastrointestinal Endoscopy" are defined as follows:

- To take account of recent advances in evidence-based medicine and recognized sedation and monitoring procedures in the implementation of the guideline.

- To compare drug therapies with various substances with respect to their efficacy and effectiveness and to their risk profiles (especially in relation to individual risk groups).

- To describe patient preferences, and to establish quality management of sedation with appropriate monitoring and incident management.

- To support doctors and patients in medical decision making with evidence-based and formal consensus recommendations.

- To support patient involvement in therapy decisions, taking their individual needs into account.

- To comprehensively implement multidisciplinary, quality-assured, and sector-spanning care of patients who need sedation during endoscopy.

- To support the documentation of complications arising during sedation.

- To systematically consider recommendations in training, further education, and continuing education, and in quality management systems.

- To create basic contents for targeted training, further education, and continuing education for physicians and healthcare staff.

- To systematically consider the recommendations and hence the quality indicators derived from them in external, comparative quality assurance and standardization of documentation standards.

- To comprehensively implement quality-assured patient care during sedation for gastrointestinal endoscopy.

- To optimize patient safety.

The guideline is intended to complement and link up with the already existing recommendations on sedation for gastrointestinal endoscopy by nonanesthetists [9-11,19-25], and to the other projects and measures mentioned above, with the aim of improving patient safety in the medium and long term.

\section{Organizational procedure and fundamental} methodology of the consensus process (short version of the guideline report)

After being commissioned by the DGVS, the organizational procedure was discussed with the vice chairman of the AWMF (Association of the Scientific Medical Societies in Germany), Dr. Ina Kopp, who also advised on methodology in the project. On 10 January 2007 the guideline project was registered at the AWMF (AWMF Register No. 014/021).

\section{Guideline steering committee and its tasks}

The composition and tasks of the guideline steering committee were defined as follows by the coordinators of the professional association with overall responsibility: 


\begin{tabular}{ll}
$\begin{array}{l}\text { Section/topic complex } \\
\text { Working group I: Indications/goals/known risks/patients/quality goals }\end{array}$ & $\begin{array}{l}\text { Working group, spokespersons } \\
\text { Jung, Seifert, Domagk, } \\
\text { - Goals }\end{array}$ \\
- Known risks & \\
- Patient aspects & \\
- Quality goals & Meining, Heinrichs, von Delius, \\
Working group II: Pharmacology & Martin, Radke \\
- Sedatives & \\
- Analgesics & \\
- Drugs acting on the autonomic nervous system & \\
- Combination therapies & \\
- Administration techniques & Arnold, Hartmann, Kraus, Radke, \\
Working group III: Structure quality & Wehrmann \\
- Personal requirements & \\
- Personnel requirements & \\
- Equipment requirements & Sieg, Heinrichs, Beilenhoff, Ehlers, \\
Working group IV: Process quality & Hofmann, Kähler, In der Smitten \\
- Information, consent & \\
- Performance of sedation & \\
- Monitoring, clinical observation, control & \\
- Emergency management & \\
Working group V: Outcome quality & Riphaus, Hermans, Bitter, Faiss, \\
- Discharge criteria & Wigginghaus, Rösch \\
- Fitness for road traffic/fitness to work & \\
- Documentation, external quality assurance, benchmarking & \\
\hline
\end{tabular}

Table 2 Section structure of the working groups of the $\mathrm{S} 3$ guideline 2008.
Guideline coordination: Dr. Andrea Riphaus, Hannover, Prof. Dr. Till Wehrmann, Hannover

Project management: Dr. Andrea Riphaus, Hannover, Prof. Dr. Till Wehrmann, Hannover, Birgit Weber, Hannover

Methodological support: PD Dr. Ina Kopp, AWMF, Marburg

The tasks of the steering committee included contacting and giving feedback to the professional associations and organizations involved, implementing methodological specifications for stage 3 guidelines using a project plan, administering the financial resources, supporting the work on content by the experts, consolidating and editing the text drafted by the experts of the working groups, and preparing the guideline methods report.

\section{Selection criteria for the circle of experts, the working groups, and their tasks}

The guideline group was convened by the coordinators. All professional associations, task forces, and organizations directly relating to the subject of the S3 guideline were contacted. They were asked to appoint experts as members who would represent them in the voting process (consensus process) and who would work on contents in the groups on specific topics (for members, see Table 1 and 2 ).

All experts were chosen and invited according to their expertise and professional qualifications. The goal was to guarantee a multidisciplinarity and multiprofessionality within the guideline group that was appropriate for the guideline with respect to its content and application. A representative of self-help organizations was from the beginning actively integrated in the guideline preparation process in order to give stronger profile to the patients' perspective.

\section{Systematic search for evidence}

The literature search was carried out in a decentralized manner within the working groups with the support of the guideline coordination office. Search strategies for the preparation of the guideline were defined as follows:
Table 3 Literature search.

\begin{tabular}{|c|c|c|}
\hline Topic complex & $\begin{array}{l}\text { References initially } \\
\text { identified }\end{array}$ & $\begin{array}{l}\text { References rated } \\
\text { as relevant for the } \\
\text { guideline }\end{array}$ \\
\hline I: Indications & 68 & 8 \\
\hline II: Pharmacology & $\begin{array}{l}3179 \text { (without } \\
\text { narrative reviews) }\end{array}$ & 72 \\
\hline III: Structure quality & 142 & 28 \\
\hline IV: Process quality & 335 & 86 \\
\hline V: Outcome quality & 355 & 16 \\
\hline
\end{tabular}

- Databases: Pubmed, Cochrane Library

- Search terms:

- General: "sedation OR conscious sedation" and "endoscopy

OR gastrointestinal endoscopy"

- Working-group-specific ( Table 3)

- Time period: $1990-2007$

In this way, 4079 publications were identified. After a preview by the heads of the working groups, 210 sources were chosen for evaluation. Publications not in English or German and ones with irrelevant content were not included. In addition, a manual search was done and relevant publications were added by members of the working groups. This led to the inclusion of 23 additional publications in the guideline. All sources were entered into a literature database by the guideline coordination office. Fortyfour publications were relevant for more than one topic and were separately evaluated with respect to each; some of these therefore have more than one entry in the evidence tables.

In addition to the literature search, a targeted guideline search was done according to the following strategy:

- Databases: Pubmed and Guidelines International Network (GIN)

- Search terms: "sedation AND gastrointestinal endoscopy"

- Time period: $1990-2007$

Eleven publications were identified in this way. 
Table 4 Simplified schema of derivation of evidence level and recommendation grade.

\begin{tabular}{|c|c|c|c|c|}
\hline \multirow[t]{2}{*}{ CEBM evidence level } & \multicolumn{2}{|c|}{ Simplified definition of source } & \multirow[t]{2}{*}{ Recommendation grade } & \multirow[t]{2}{*}{ Description } \\
\hline & Therapy & Diagnostics & & \\
\hline I & $\begin{array}{l}\text { Randomized controlled } \\
\text { studies }\end{array}$ & Validation cohort studies & A & Strong recommendation \\
\hline II & $\begin{array}{l}\text { Controlled studies without } \\
\text { randomization }\end{array}$ & Explorative cohort studies & B & Recommendation \\
\hline III-V & \multicolumn{2}{|c|}{ Observational studies, expert opinion } & 0 & Recommendation open \\
\hline
\end{tabular}

The evaluation of the relevant literature was done by members of the individual working groups ( $\bullet$ Table 2 and $\mathbf{3}$ ).

\section{Classification of evidence level, recommendation grade, and consensus size}

The evidence classification of the present guideline is based on the evidence categories of the Oxford Centre for Evidence Based Medicine (see Appendix 1). The recommendations were graded according the current methods report of the Program for National Health Care Guidelines (see Appendix 2).

The terms used in the guideline and the table showing the derivation of evidence level and recommendation grade are summarized and simplified in $\bigcirc$ Table 4.

The formal consensus procedure employed the techniques of the nominal group process, formal consensus conferences, and the Delphi technique. The voting process with all contributions of content as well as the voting results and evaluation of consensus strength were documented and rationales provided ( $\bullet$ Table 5 ).

\section{Consensus procedure}

During the first consensus process in January 2007 in Hannover, the methodological concept for the guideline preparation, the structure, and the key questions were determined. Subsequently, the working groups were appointed (see $\odot$ Table 2). Furthermore, the guideline group was checked for completeness. The appointment of further experts or inclusion of other professional groups was not considered necessary by the guideline group.

In a second consensus process, members of the working groups chose sources, formulated key statements and recommendations, demonstrated evidence levels on which they are based, and expressed recommendation grades based on primary literature. In the second formalized consensus process the suggested key statements and recommendations including the grading were discussed. The recommendation grades were then adjusted in the light of standard consensus criteria. Where evidence levels diverged from the recommendation grade, reasons were given. In addition to the recommendation grade, all key statements and recommendations are given as evidence level and consensus size. The process of reaching consensus was done at one 2-day and one 1-day structured consensus conferences of the entire guideline group, which took place in June and September 2007 in Hannover and Frankfurt am Main, respectively.

The consensus conferences were structured in a series of steps:

Part 1: Short presentations

- Introduction to the methods of the formal consensus process by the presenter

- Display of medical/scientific state of knowledge for each topic complex by the heads of the working groups

- Opportunity to ask questions on the methodological procedure and on the rationale of the results in the plenary session
Table 5 Definition of consensus size.

$\begin{array}{ll}\text { Strong consensus } & \geq 98 \% \text { of participants } \\ \text { Consensus } & >75 \%-98 \% \\ \text { Majority agreement } & >50 \%-75 \% \\ \text { No consensus } & \leq 50 \% \text { of participants }\end{array}$

\section{Part 2: Structured consensus finding}

- Proceeding section by section, every key statement and every recommendation is called individually by the presenter

- Registration of comments from the plenary session by the presenter

- Clarification and rationale of alternative suggestions

- Preliminary vote on initial draft and all alternatives

- Determination of discussion points and differences of opinion

- Debate and discussion

- Final vote

The key statements in Working Group II Pharmacology and Working Group IV Process Quality that were not put to vote at these meetings were voted on in a modified Delphi process.

The addressees were all members of the guideline group. The following details were requested for each section of the guideline:

- Agreement

- Disagreement

- Concrete, well-argued proposals for modification, including references

In the Delphi process all members of the guideline group were additionally asked to give quality goals which they thought were relevant. These goals were based on recommendations with high evidence levels [1,2].

The results of the first survey (first Delphi round) were summarized and then presented to the guideline group. The sections on which there was no consensus and the suggestions for modifications were put to the vote again in July 2008 (second Delphi round).

The final consensus of the complete guideline text was also done in writing in a modified Delphi process in August 2008.

Finally, in September 2008 the complete guideline text was presented for acceptance to the executive committees and board of directors of the participating professional associations and organizations.

\section{Circulation and implementation of the guideline}

The S3 guideline "Sedation in Gastrointestinal Endoscopy" will be published in the following formats:

1. Short version in German and English (journals with peerreview process), short version of the patient information

2. Complete version (short, long, and patient version, and methods report) on the internet (www.awmf-leitlinien.de; www.dgvs.de, www.dgai.de, www.dgvc.de, www.bng.de, www.dccv.de, www.degea.de) 
3. Complete version in English on the internet (Guidelines International Network, GIN: www.g-i-n.net)

The S3 guideline will be published in electronic and printed form. It will be made freely accessible with the following elements via the internet portals of the AWMF (www.awmf-leitlinien.de, AWMF-register no. 021/014), the German Society for Digestive and Metabolic Diseases (www.dgvs.de, category "Leitlinien der DGVS"), and the German Society for Anesthesiology and Intensive Care Medicine (www.dgai.de):

- Long version: complete text, recommendations, and algorithms with detailed background information and short methods report on the rationale for the individual recommendations and comprehensive list of references

- Short version as an appendix to the long version: summary of the health care recommendations including the evidence levels and the recommendation grades

- Guideline methods report: detailed demonstration of the development process methodology

The special formats are an integral part of the implementation strategy. Clinicians and others are explicitly encouraged to use the publications listed at $1-3$ above to support implementation of the guideline. This would include, for example:

- Implementation of the algorithms in hospitals and practices (clinical local treatment pathways, training, and corresponding local development of aids: e.g., pocket formats for lab coats; inclusion in supporting media: inclusion in hospital and private practice electronic information systems as part of quality management)

- Inclusion of the guideline in existing and planned training programs (e.g., simulation workshops on sedation analgesia and complication management)

- Implementation of patient information as part of public relations work: e.g., postcard formats, display on the internet, leaflets

Circulation and implementation of the guideline will continue to be supported by the steering committee by:

- Public relations work by the committee that prepared the guideline:

- Press releases to the scientific information service idw (idw-online.de);

- Press conferences

- Direct approach to the target users of the guideline:

- Contributions in professional journals and books

- Conferences, presentations, seminars

- Support in preparing materials for training and further education (CME-accrediting according to the state medical association)

Funding of the guideline and statement of possible conflict of interest

The preparation of the S3 guideline was supported by a grant of 30000 euros from the DGVS. These funds were used for personnel costs (guideline office), costs for strategy meetings and consensus processes (traveling expenses for all participants, rent for meeting rooms, technical services, and catering), costs for office supplies, and fees for external experts consulted for methodological support. The guideline was produced independently of the funding organization. We thank the authors and participants in the consensus process for their entirely voluntary work. All members of the guideline group gave written statements on possible conflicts of interest, particularly with respect to commercial companies.
Period of validity and update procedure

The guideline is valid until December 2012 at the latest. A complete revision and new edition is planned at this time. The guideline groups will watch for new findings that may make the revision of individual sections or recommendations necessary, and the coordinator would be glad to receive relevant information in this regard from users of the guideline. The aim is produce continual updates as necessary.

The date of the publication, the date of the next planned revision, and notification of planned and/or interim revised versions will be displayed in the publicly accessible directory of the AWMF ( http://www-awmf-leitlinien.de). The valid version with always be the most recent one according to the AWMF register.

\section{Indications/goals/known risks/patients/quality goals $\nabla$}

\subsection{Recommendation on sedation choices}

Recommendation: Sedation should be offered to every patient before endoscopy. The advantages and disadvantages should be discussed in detail.

Recommendation grade A, evidence level 5, consensus

Comments: Every patient has the right to an endoscopic examination that is as painless and stress-free as possible. It therefore appears ethically unjustifiable to withhold sedation from patients on principle [26]. Endoscopic examinations can be unpleasant, which makes sedation desirable or advisable. Especially during long, difficult endoscopic interventions (e.g., ERCP, difficult resection or drainage procedures) it is important to avoid involuntary patient movement. Thus, sedation should on principle be offered to every patient. After the patient has been given adequate information about the facts of sedation, his or her wishes should be taken into account so far as possible.

Recommendation: On principle, simple endoscopic examinations (gastroscopy, sigmoidoscopy, colonoscopy, etc.) can be performed without sedation in suitable patients.

Recommendation grade A, evidence level 2b, strong consensus

Comments: One randomized controlled study [27] and two prospective cohort studies $[28,29]$ underlie these recommendations. However, the rate of patient agreement to unsedated colonoscopy was only $88 \%[28,29]$. In another study only $20 \%$ of respondents agreed to colonoscopy without sedation. Male sex, higher education, and lower anxiety were positive predictive factors for a preference on the part of the patient for unsedated colonoscopy [30].

\subsection{Recommendation on indications for sedation}

Recommendation: The following should be considered when deciding for or against sedation and/or analgesia:

- Patient characteristics (risk profile, any co-morbidities, preferences)

- Nature of endoscopic intervention (reason, duration, invasiveness and complexity)

- Structural requirements

Recommendation grade A, evidence level 5, strong consensus

\subsection{Recommendation on examination quality}

Recommendation: No statement can be made on how performance or nonperformance of endoscopic sedation affects the rate of complications related to endoscopic interventions.

Evidence level 5, strong consensus 
Comments: Undoubtedly, premedication is not necessary for all endoscopic gastroenterological procedures. Ultimately it depends on the nature of the examination and its duration, complexity, and invasiveness. Premedication contributes greatly to the comfort of the examination for both patient and physician, and in some cases, especially complex therapeutic interventions, it may be what allows the intervention to be performed successfully and with low risk. Patient preference also plays an important role that should not be underestimated. Experiences of previous endoscopic examinations, anxiety, and the patient's understanding of the procedure all need to be taken into account. In addition, there are often cultural variations around the world with regard to sedation for gastrointestinal endoscopy. For example, in the United States and the United Kingdom, up to $88 \%$ of endoscopic examinations are done under sedation $[1,2]$. In contrast, in Germany and Switzerland the sedation frequency reported in the 1990s was much lower (about 9\%) [3,4], although it went up with the complexity of the examination. However, recent survey results show a pronounced increase in sedation frequency for endoscopic interventions in Germany (up to 87\%) [5]. This is probably due to the increase in interventional procedures and also to patient preference, e.g., during colorectal cancer screening.

However, almost no studies exist that compare the safety of diagnostic and therapeutic endoscopy with to those without sedation (see Evidence $\bullet$ Table $\mathbf{1}$ and $\mathbf{2}$ in the methods report). An American study failed to reach the intended comparison goal because of lack of patient acceptance (high preference for sedation) [27]. The results of a German study showed that colonoscopy can be done without sedation in more than $90 \%$ of cases with a low risk of complications [28]. However, in general the majority of patients prefer premedication $[28,31,32]$. Sedation does not seem greatly to influence the risk of the endoscopic procedure itself. A prospective study by Dillon et al. [33] of colonoscopy in 136 children under general anesthesia showed that the perforation rate was no higher than for adults under sedation. The claim that fewer perforations occur during colonoscopy if pain perception is maintained has therefore not been confirmed.

\subsection{Recommendation on risk assessment and structure quality}

\subsubsection{General}

Sedating and analgesic drugs can induce overlapping, not always clearly distinguishable sedation states ranging from minimal sedation (anxiolysis) to general anesthesia.

Physicians who are not anesthesiologists are not allowed to perform sedation and/or analgesia procedures that would reach a planned degree of sedation that affects or eliminates life-preserving reflexes. Planned general anesthesia (with loss of consciousness/protective reflexes) should be left to anesthesiologists. If, in the occasional case, it happens that a degree of sedation is reached that affects or eliminates life-preserving reflexes (gener-

\begin{tabular}{|c|c|c|}
\hline Grade & Term & Description \\
\hline 0 & $\begin{array}{l}\text { Alert } \\
\text { and calm }\end{array}$ & \\
\hline-1 & Sleepy & $\begin{array}{l}\text { Not completely alert, but at least awake } \\
\text { phases (eyes open, eye contact) lasting at } \\
\text { least } 10 \mathrm{~s} \text { when patient is addressed }\end{array}$ \\
\hline-2 & Mild sedation & $\begin{array}{l}\text { Awake phase (eyes open, eye contact) } \\
\text { lasting less than } 10 \mathrm{~s} \text { when patient is ad- } \\
\text { dressed }\end{array}$ \\
\hline-3 & $\begin{array}{l}\text { Moderate } \\
\text { sedation }\end{array}$ & $\begin{array}{l}\text { Movement or eye opening when patient is } \\
\text { addressed (but no eye contact) }\end{array}$ \\
\hline-4 & $\begin{array}{l}\text { Deep } \\
\text { sedation }\end{array}$ & $\begin{array}{l}\text { No reaction when patient is addressed, but } \\
\text { movement or eye opening when physically } \\
\text { stimulated (shaking shoulder or rubbing } \\
\text { sternum) }\end{array}$ \\
\hline-5 & No reaction & $\begin{array}{l}\text { No reaction when patient is addressed or } \\
\text { physically stimulated }\end{array}$ \\
\hline
\end{tabular}

al anesthesia), and if the intervention is to be continued, an anesthesiologist should be called in.

Despite the continuum of sedation analgesia, with transitions that cannot always be reliably controlled, various levels can nevertheless be differentiated. The degree (depth) of sedation can be assessed and classified using a validated scale. In Germany, the modified Richmond Agitation-Sedation Score Scale (RASS Scale) [34] ( Table 6) is commonly used in the anesthesiology community, whereas gastroenterologists use the classification of sedation stages issued by the American Society of Anesthesiologists [19] ( Table 7).

Recommendation: The type and intensity of the sedation and the drug used should be selected according to the type of intervention and the patient's ASA grade and individual risk profile. There are particular requirements in respect of facilities, equipment, and qualified personnel.

Unless the requirements defined under Section 2.3.4 "Monitoring/ structure quality" are met, once the risk-benefit balance and the patient's wishes have all been weighed up, sedation should either be avoided or, if sedation is indicated and/or the patient wants sedation, the patient should be transferred to a facility that does fulfill these requirements.

Recommendation grade A, evidence level 5, strong consensus

Comments: The American Society of Anesthesiologists and the American Society of Gastroenterologists [19,35] recommend carrying out a risk assessment before the examination begins of any cardiovascular and respiratory problems that could occur during endoscopy. This includes a detailed history including questions about the following:

1. Diseases of the cardiovascular and respiratory system, stridor, snoring, sleep apnea syndrome

Table 7 Stage of sedation. Modified from the American Society of Anesthesiologists [19].

\begin{tabular}{|c|c|c|c|c|}
\hline & Minimal (anxiolysis) & Moderate & Deep & Anesthesia \\
\hline $\begin{array}{l}\text { Reaction to being } \\
\text { addressed }\end{array}$ & $\begin{array}{l}\text { Patient reacts appropriate- } \\
\text { ly to verbal commands }\end{array}$ & $\begin{array}{l}\text { Somnolence, reaction to } \\
\text { louder commands with ad- } \\
\text { ditional tactile stimulation } \\
\text { if necessary }\end{array}$ & $\begin{array}{l}\text { Somnolence, hard to wake, } \\
\text { purposeful response after } \\
\text { repeated or painful stimu- } \\
\text { lation }\end{array}$ & $\begin{array}{l}\text { Patient cannot be woken, } \\
\text { not even in response to } \\
\text { pain stimuli }\end{array}$ \\
\hline Spontaneous breathing & Not influenced & Adequate & $\begin{array}{l}\text { Respiratory function mildly } \\
\text { restricted }\end{array}$ & $\begin{array}{l}\text { Inadequate, ITN or larynx } \\
\text { mask necessary }\end{array}$ \\
\hline
\end{tabular}


2. Complications on previous occasions when sedatives/analgesics, regional and/or general anesthesia were administered

3. Drug allergies, current medication, and possible drug interactions

4. Most recent meal: when and what was eaten

5. Tobacco, alcohol, drug consumption

A physical examination should be done that in addition to vital signs includes auscultation of heart and lung.

The ASA classification [36] ( Table 8) and the structure quality are the basis of the existing guidelines [9-11,19,20,36-41].

Patients in ASA grade III or higher have an increased risk of complications due to sedation or the endoscopic intervention ( $\bullet$ Table 9 ).

The upgrade of the abovementioned statement to a recommendation grade $A$ when the evidence level is 5 is due to a $2 \mathrm{~b}$ evidence level for ASA grade and co-morbidity and to patient safety considerations.

\subsection{Recommendation on anesthesia/intubation}

Recommendation: Calling in an anesthesiologist should be considered for patients with a high risk profile. This includes: high ASA grade (III-IV) and a difficult endoscopic intervention or the presence of pathological anatomical features associated with a higher risk of airway obstruction during the intervention (e.g., craniofacial malformation; lingual, laryngeal, or hypopharyngeal tumor; severely restricted mobility of the cervical spine; severely restricted mouth opening $<3 \mathrm{~cm}$; Mallampati stage 3 or 4 ; or a restricted hyoid-to-chin distance $<4 \mathrm{~cm}$ ).

Recommendation grade A, evidence level 5, consensus

Comments: The risk profile includes pathological/anatomical features that can lead to respiratory problems and could make support by mechanical ventilation or artificial respiration difficult. In addition, existing guidelines give recommendations on the assessment of increased risk of airways obstruction $[9,19,35$, 36,42 ] in patients with previous problems related to anesthesia or sedation. These are:

1. Patients with stridor, snoring, sleep apnea.

2. Patients with malformation of the facial bones, e.g., PierreRobin syndrome or Down syndrome.

3. Patients with malformation of the mouth, such as small opening ( $<3 \mathrm{~cm}$ for adults), agomphiasis, projecting anterior teeth, missing or broken teeth, strongly curved palate with macroglossia, tonsil hypertrophy, or a uvula that is not visible.

4. Patients with abnormalities of the neck, such as obesity involving the neck and face, short neck, restricted neck mobility, reduced hyoid-to-chin distance ( $<4 \mathrm{~cm}$ for adults), neck tumors, disease or trauma of the cervical spine, tracheal alterations, or advanced rheumatoid arthritis.

5. Patients with jaw malformations such as micrognathia, retrognathia, the jaw typical of Down syndrome, or pronounced malocclusion.

6. Due to their risk profile, the requirements for sedation are also expected to be higher for persons with alcohol abuse, drug abuse, or on chronic medication, and also for patients with a high ASA grade and/or for persons that are not able to cooperate.

\subsection{Recommendation on protective intubation}

Recommendation: Deep sedation leads to impairment of the protective reflexes (pharyngeal reflex, cough reflex). This can promote aspiration. In special situations in emergency endoscopy where
Table 8 ASA classification.

\begin{tabular}{ll} 
Grade I & Healthy individual \\
\hline Grade II & Mild disease, not limiting daily activities \\
\hline Grade III & Severe disease, limiting daily activities \\
Grade IV & Severe disease, life-threatening \\
Grade V & $\begin{array}{l}\text { Unlikely to survive for } 24 \text { hours regardless of surgical } \\
\text { intervention }\end{array}$
\end{tabular}

Table 9 Characterization of ASA classification grades III - IV in relation to patient-specific risk factors.
Decompensated heart failure
Coronary heart disease
Heart valve disease/replacement
Liver and kidney failure
Pulmonary disease
Coagulation disorders

there is increased risk of aspiration under sedation (e.g., severe upper gastrointestinal bleeding), tracheal intubation should therefore be considered, however, it should be born in mind that prophylactic intubation may itself be associated with an increased risk of pneumonic infiltrates.

Recommendation grade B, evidence level 4, strong consensus

Comment: It is a basic fact that deep sedation leads to restriction of the protective reflexes. For this reason, if additional risk of aspiration is present (e.g., during emergency endoscopy for upper gastrointestinal bleeding), tracheal intubation in order to avoid aspiration seems sensible. However, because there are no highquality studies that prove that the advantages of this procedure outweigh the disadvantages, it is not possible to issue a general recommendation in this respect.

In a retrospective case-control study by Koch et al. [43] of a total of 62 patients, 42 of whom underwent prophylactic endotracheal intubation before the start of endoscopy for variceal hemorrhage, pneumonic infiltrates were subsequently demonstrated in $17 \%$ of the intubated patients. This was not the case in the nonintubated patients. In addition, overall mortality was higher in the group that underwent prophylactic intubation ( $21 \%$ vs. $5 \%$ ). In another retrospective case-control study by Rudolph et al. [44] including a total of 220 patients, no significant difference was seen in the frequency of pneumonic infiltrates and overall mortality between the intubated and nonintubated groups. However, deaths due to aspiration were higher among patients who did not undergo prophylactic intubation ( $2 \%$ vs. $0 \%$, respectively).

Because of lack of clarity in such retrospective analyses about how patients were allocated between the groups, and thus a possible bias (severely ill patients are more likely to undergo intubation), such studies are only of limited value.

\subsection{Recommendation on patient positioning}

Recommendation: Just as for general anesthesia during surgery, it is important to ensure that sedated patients are positioned correctly in order to avoid position-related damage.

Recommendation grade A, evidence level 5, strong consensus

Comments: On the whole, damage due to positioning is not a major issue in gastrointestinal endoscopy. Nevertheless, it should be avoided as a matter of principle. Especially when under mild se- 
Table 10 Patient satisfaction with sedation with propofol compared to the use of benzodiazepines/opioids

\begin{tabular}{|c|c|c|c|c|}
\hline Author & Type of exam & Sedation regimen & $\begin{array}{l}\text { Patient } \\
\text { number }\end{array}$ & Differences \\
\hline Roseveare et al. 1998 [56] & $\begin{array}{l}\text { Patient-controlled sedation with } \\
\text { propofol during colonoscopy }\end{array}$ & Diazepam/pethidine & 66 & $\begin{array}{l}\text { Patient satisfaction equal in both } \\
\text { groups }\end{array}$ \\
\hline Ulmer et al. 2003 [57] & NAPS during colonoscopy & Midazolam/fentanyl & 100 & $\begin{array}{l}\text { Patient satisfaction comparable in } \\
\text { both groups ( } 9.3 \text { vs. } 9.4, P>0.5 \text {, } \\
10-\mathrm{cm} \text { visual analog scale ) }\end{array}$ \\
\hline Vargo et al. 2002 [58] & NAPS during ERCP & Midazolam/meperidine & 75 & $\begin{array}{l}\text { Patient satisfaction equal in both } \\
\text { groups }\end{array}$ \\
\hline Sipe et al. 2002 [59] & NAPS during colonoscopy & Midazolam & 80 & $\begin{array}{l}\text { Patient satisfaction significantly } \\
\text { higher with propofol ( } 9.3 \text { vs. } 8.6 \text {; } \\
P<0.05,10 \text {-point visual analog scale) }\end{array}$ \\
\hline Weston et al. 2003 [60] & $\begin{array}{l}\text { NAPS during EGD in patients with } \\
\text { liver cirrhosis }\end{array}$ & Midazolam & 20 & $\begin{array}{l}\text { Patient satisfaction significantly } \\
\text { higher with propofol }(P<0.05)\end{array}$ \\
\hline
\end{tabular}

NAPS, nurse-administered propofol sedation.

dation, patients can move involuntarily; they should therefore be appropriately secured.

Damage due to positioning is most likely to occur in patients undergoing ERCP (prone or left-lateral position) or when they are being transferred from the examination table to the bed.

There is no direct evidence on the subject of damage due to positioning in endoscopy; the recommendation is based on the joint recommendation of the Professional Association of German Anesthesiologists and the Professional Association of German Surgeons [45].

\section{Sedatives/analgesics/drugs acting on the autonomic nervous system/combination therapy/methods of administration}

$\nabla$

2.1 Acceptance by the patient and the endoscopist

2.1.1 Patient acceptance/satisfaction

Recommendation: Sedation increases the patient's comfort and hence his or her acceptance of the endoscopic intervention. The ideal sedation seems to be one that leaves no memory of unpleasant sensations but at the same time has a short duration of action. Recommendation grade A, evidence level 1b, strong consensus

Comments: Endoscopy under sedation is preferred by $40 \%-60 \%$ of patients [46]. Especially young, anxious female patients benefit from sedation $[27,47]$. Patients want first and foremost complete freedom from pain, followed by the wish to wake up as soon as possible [48].

A study by Abraham et al. [49] showed that gastroscopies under sedation were followed by fewer repeat procedures and were better accepted by patients. The higher rate of patient acceptance owing to sedation during endoscopic examinations has also been demonstrated in other studies [50-54].

However, when benzodiazepines are used for sedation during gastroscopy, patients may have discomfort (especially retching and gag reflex) that the endoscopist may not notice. In a study by Walmsley et al. [55], the incidence of discomfort of this kind that remained unnoticed by the endoscopist was $12 \%$.

In colonoscopy, too, "moderate" sedation using midazolam can sometimes allow the patient to feel pain [27] without the endoscopist's necessarily realizing this.

In contrast, when propofol is used for sedation during esophagogastroduodenoscopy (EGD), colonoscopy, and ERCP, patient satis- faction is as good as or better than when midazolam is used (๑ Table 10).

\subsubsection{Endoscopist satisfaction}

Recommendation: Sedation increases the practicability and the completeness of the examination and thus improves examiner satisfaction (especially in interventional endoscopy).

Recommendation grade A, evidence level 1b, strong consensus

Recommendation: In interventional endoscopy, propofol is superior to midazolam with respect to endoscopist satisfaction.

Recommendation grade $\mathrm{B}$, evidence level $2 \mathrm{~b}$, strong consensus

Comments: Sedation using midazolam during EGD can lead to high acceptance by the patient [61] but to dissatisfaction on the part of the endoscopist [62]. By combining midazolam with opiates, endoscopist satisfaction can be improved.

A randomized study by Laluna et al. [63] of 107 patients compared midazolam combined with placebo and midazolam combined with meperidine for EGD. Endoscopist satisfaction was significantly better with the combination regimen $(P<0.001)$, whereas little difference was seen in patient acceptance.

A randomized study by $\mathrm{Ng}$ et al. [64] of 80 patients investigated patient tolerance and endoscopist satisfaction during patientcontrolled sedation with propofol or midazolam for colonoscopy. The use of propofol led to significantly higher endoscopist satisfaction $(P=0.01)$.

Especially for longer and more complex interventions [65], deep sedation may be needed to help ensure that examinations can be done safely without unwanted and uncontrollable involuntary movement of the patient.

Two randomized studies by Jung et al. [66] and Wehrmann et al. [67] that investigated sedation for ERCP using propofol or midazolam showed significantly higher endoscopist satisfaction with propofol.

However, increasing the depth of sedation, achieved by raising the dose of the various substances, also increases the incidence of unexpected/unwanted side effects (see dose recommendations in the product information of the various manufacturers, - Table 11, and Section 2.2.3.1). 


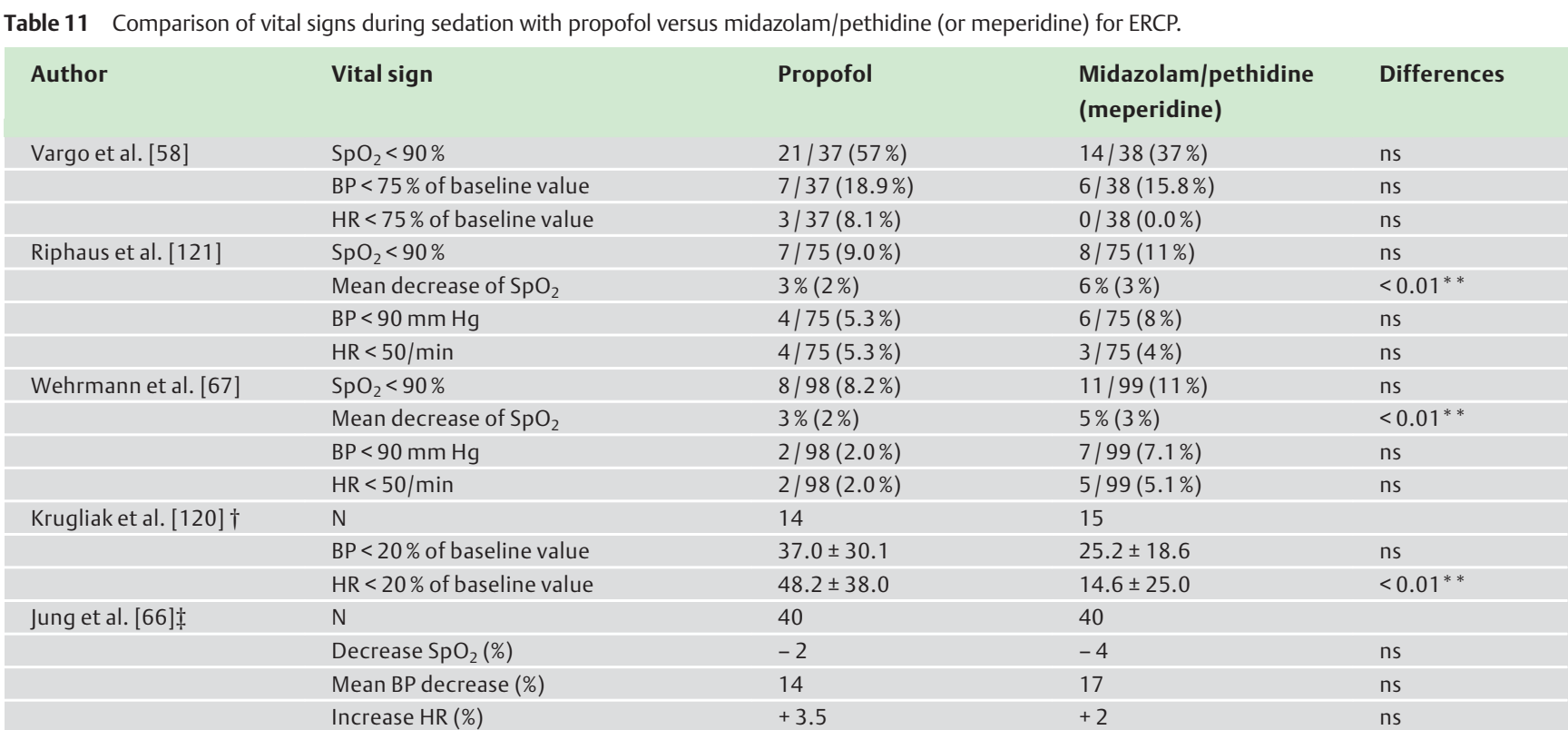

BP, blood pressure; HR, heart rate; ns, not significant; **, significant $(P<0.01)$. $\dagger$ Propofol group $n=14$, midazolam/pethidine (meperidine) group $n=15$.

$\ddagger$ In both groups $n=40$

\subsection{Monotherapies}

\subsubsection{Propofol}

\subsubsection{General}

Propofol is a sedative without analgesic effect. The sedating effect of propofol is based on the accumulation of $\gamma$-aminobutyric acid (GABA) because of reduced dissociation of the GABA receptors. The exact pharmacodynamic mechanisms of propofol are still not completely understood. Propofol is extremely lipophilic and develops its effect within 30-45 seconds. The sedation effect lasts only $4-8$ minutes after administration because the drug is rapidly metabolized by the liver. These characteristics (quick onset of action with short effect duration) make it a suitable sedative for gastrointestinal endoscopy $[6-8,59,60,68-70]$. The effect of propofol is individually variable depending on age $[71,72]$, body weight, co-morbidity, or concomitant medication. Occasionally a single dose can take a patient right through several levels of sedation ( Table 6 and 7) and trigger short-term apnea [73]. However, in contrast to midazolam, no antagonist exists for propofol, and therefore all endoscopy teams that use propofol for sedation have to be able to control apnea rapidly (see Section 4.4, "Management of sedation-related adverse events").

In addition to hypoxemia, typically hypotension can occur when propofol is used [12] ( $\odot$ Table 11, Section 2.2.3.1).

Rare occurrences are bacteremia due to improper drug storage (with consequent bacterial contamination), which can cause sepsis, and occasional cases of pancreatitis $[74,75]$. A so-called propofol infusion syndrome (with rhabdomyolysis) has also been described, though so far it has only occurred with long-term administration ( $>48$ hours) at high doses ( $>4 \mathrm{mg} / \mathrm{kg}$ per hour) [76]. Propofol is contraindicated in patients with a known allergy to albumin, soy protein, or sulfite.

Propofol is initially given as bolus to induce sedation. To maintain sedation, it is then either given as repeated boli or continuously administered using a perfusor.

\subsubsection{Methods of propofol administration}

Alternative modes of administration to the intermittent bolus mode that is currently most often used in German endoscopy are perfusor administration (with an initial single bolus for initiation), so-called "target-controlled infusion" (TCI), patient-controlled sedation (PCS), and "computer-assisted personalized sedation" (CAPS). Intermittent bolus administration and perfusor administration are standard procedures, while the other methods are still experimental in nature, at least with respect to their use in endoscopy.

\subsection{Intermittent propofol bolus administration}

With the intermittent bolus administration method, sedation is induced with an intravenous bolus adjusted to the weight and, if necessary, the age and any co-morbidity of the patient (e.g., $40 \mathrm{mg}$ at $<70 \mathrm{~kg}$ b. w. or $60 \mathrm{mg}$ at $\geq 70 \mathrm{~kg}$ b. w.); thereafter, repeated boli of, e.g., $10-20 \mathrm{mg}$ according to patient need are given to maintain the desired depth of sedation. If necessary, a benzodiazepine and/or opiate can additionally be given to induce sedation (see Section 2.3, "Combination therapies"). The intermittent bolus administration method was used in almost all published studies on the sedation efficacy of propofol for endoscopic examinations/treatments compared to that of other drugs (e.g., midazolam), and is therefore currently the best documented and most often used form of administration in endoscopy.

\subsection{Continuous propofol administration using perfusor systems}

For this mode of administration, too, a bolus of propofol adjusted for body weight and, if necessary, age and co-morbidity is given to induce sedation (if necessary, in combination with other drugs). Sedation is then (usually) maintained by weight-adjusted continuous propofol infusion. Dosage is according to the desired depth of sedation and the individual patient's risk profile. Most systems allow additional propofol boli as needed. Special perfusor systems for anesthesia automatically calculate the maintenance dose of propofol $1 \%$ or $2 \%$ solution required for a specified 
sedation depth once various patient parameters have been entered (e.g., weight, height, age).

Perfusor administration of propofol is currently the method most often used to maintain total intravenous anesthesia worldwide. However, so far there are few studies on its use in endoscopy [77]. So far as we know, no randomized comparison study between perfusor administration and intermittent bolus administration in endoscopy has been carried out.

Recommendation: The intermittent bolus method of administration may currently be regarded as the standard procedure for the use of propofol in endoscopy. Propofol administration using a perfusor is well documented in anesthesiology and is considered standard for totally intravenous anesthesia. However, few published data exist regarding its use in endoscopy.

Recommendation grade $\mathrm{A}$, evidence level $2 \mathrm{~b}$, strong consensus

\subsection{Patient-controlled sedation analgesia}

Patient-controlled administration of drugs originated in pain therapy and is today standard in postoperative analgesia (e.g., in the concept of "fast-track surgery"). With the help of a programmable infusion pump, patients can intravenously administer to themselves a defined dose of a drug at the press of a button. To avoid overdose, a time-delay option can be applied for repeat doses (so-called lockout mechanism).

PCS may be useful for endoscopic examinations where relatively short episodes of pain can be tolerated by the patient, such as is frequently the case during colonoscopy (e.g., sigma passage, flexure passage). Administration of short-acting drugs via these systems (e.g., the Graseby 3000 pump) is ideally suited to these cases. A combination of propofol with short-acting opiates (e.g. alfentanyl) is often used.

In randomized studies the use of a PCS system (propofol plus alfentanyl) led to similar patient satisfaction as for midazolam and meperidine [78] and diazepam and meperidine (called pethidine in Germany) [56,79]; in two other studies, even, patient satisfaction was higher than for midazolam $[64,77]$. However, in another randomized study a higher pain score was reported for PCS than for midazolam [78]. Nevertheless, fewer adverse events (oxygen undersaturation or fall in blood pressure) were observed with PCS using propofol than with diazepam $[56,79]$. In two of these studies, $97 \%$ and $78 \%$ respectively of the patients who were sedated using the PCS method for colonoscopy said they would be willing if necessary to repeat sedation with the same procedure $[80,81]$. Younger age, female sex, and low patient satisfaction were independent factors for refusal of the PCS procedure.

In a Swiss study of PCS, $35 \%$ of all patients who were approached refused to take part in the study, either because they wanted complete unconsciousness or because they did not want to take responsibility for their own drug administration [13]. However, among those patients who did take part, it was observed that a significantly lower dose of propofol was used when PCS was employed than with intermittent bolus administration by a nurse (NAPS) during colonoscopy [13].

Recommendation: If propofol is used for colonoscopy, with or without opiates, patient-controlled sedation is an alternative to bolus administration.

Recommendation grade 0 , evidence level $2 \mathrm{~b}$, strong consensus

\subsection{Target-controlled infusion}

The target-controlled infusion (TCI) method allows intravenous administration of propofol (or other drugs) using an infusion pump. The dose and infusion rate are regulated by computer
[82]. The computer system calculates the individual infusion rate from the pump needed to maintain a preset desired drug concentration in the blood, using algorithms that take account of various parameters relating to the patient (e.g., age, sex, height, weight, sedation depth). After the initial dose required to reach the desired blood concentration has been calculated, the infusion rate is adjusted during the course of sedation (the desired blood concentration is defined by the physician: this is the "open system").

With special systems the infusion rate can be varied on the basis of muscle tone, auditory evoked potentials, and/or other physiological parameters that reflect the depth of sedation, thus allowing regulation of the sedation ("closed systems").

The potential advantage of the TCI method compared to continuous infusion (with fixed dose and infusion rate) is the ability to avoid accumulation of the drug, since the infusion rate is constantly being changed.

In an evaluation by Fanti et al. [83] of 205 patients who underwent ERCP under deep sedation (without assisted ventilation), an open TCI system with propofol was used. The initial desired concentration was $4 \mu \mathrm{g} / \mathrm{ml}$, followed by maintenance by the anesthesiologist in the range $2-5 \mu \mathrm{g} / \mathrm{ml}$ during the course of the procedure. In addition, a bolus administration of fentanyl (50$100 \mu \mathrm{g}$ i.v.) was allowed. The endoscopists rated the sedation as excellent in 201 of 205 cases; only four cases of hypoxemia $\left(\mathrm{PO}_{2}<85 \%\right)$ were observed, and one case where ventilation with a mask was necessary.

In another trial, colonoscopy was performed in 16 patients using a closed TCI system where the infusion rate was controlled by means of EEG (bispectral index determination) [84]. In this study by Leslie et al. [84], a median propofol concentration of $2.3 \mu \mathrm{g} / \mathrm{ml}$ was aimed at; predominantly, a bispectral index of 80 was seen (corresponding to a mild to moderate depth of sedation).

Further studies investigated the combined use of TCI and PCS, in which the patient was able to modify the administration rate of the TCI pump by pushing a button. Positive sedation effects were reported during colonoscopy and ERCP [84-87]. However, the case numbers were small $(n=20-40)$. In a randomized study by Stonell et al. [87] that compared the TCI/PCS system to repetitive bolus administration of propofol by an anesthesiologist during colonoscopy $(n=40)$, no significant differences were found in sedation efficacy or complication rate. The total propofol dose tended to be lower in the TCI group than in the bolus group (233 vs. $288 \mathrm{mg}, P=0.05$ ).

\subsection{Computer-assisted personalized sedation}

The computer-assisted method of personalized sedation (CAPS) extends the TCI dosing of propofol by the addition of various monitoring parameters, both physiological (pulse frequency, blood pressure, $\mathrm{O}_{2}$-saturation, and exhaled $\mathrm{CO}_{2}$ ) and in the form of patient reactions to specific verbal (via headphones) and tactile stimuli (via a vibration mouse). Sedation is thus implemented and monitored entirely by computer. Currently, this system only allows the regulation of moderate sedation depths: deep sedation and anesthesia are not yet envisaged. This system is not currently licensed for clinical use in Europe.

In an initial two-center evaluation in the US and Belgium, an adequate sedation effect without complications was observed in a total of 96 patients undergoing gastroscopy or colonoscopy. Following an initial bolus administration of fentanyl (25-100 $\mu \mathrm{g})$, between $20 \mathrm{mg}$ and $350 \mathrm{mg}$ (median $70 \mathrm{mg}$ ) propofol was administered via this system [88]. 
Recommendation: TCI and CAPS have been investigated in several studies. No recommendation can be made on the value of these procedures on the basis of the data currently available.

Recommendation grade 0 , evidence level $1 \mathrm{~b}$, strong consensus

\subsubsection{Benzodiazepines}

Benzodiazepines induce anxiolysis, amnesia, and sedation, and have both anticonvulsant and muscle-relaxing effects. They act by binding to the $\mathrm{GABA}_{\mathrm{A}}$ receptor. Different benzodiazepines can have different pharmacologic characteristics (e.g., a stronger sedating effect or a stronger anxiolytic effect) [89].

\subsubsection{Diazepam}

Diazepam was the only available sedative when endoscopy started, but is now rarely used in the western world for endoscopic examinations. This is because it has a relatively long half-life compared to more recent short-acting benzodiazepines such as midazolam [90 - 92]. The main side effects of diazepam are respiratory depression [93], coughing, and dyspnea. Phlebitis can occur at the injection site, especially if water-soluble forms are used [94]. The usual dose is a single injection of 5-10 $\mathrm{mg}$ (see also dose recommendation in the manufacturer's product information).

\subsubsection{Midazolam}

Midazolam is a short-acting benzodiazepine that is still the most commonly used sedative for endoscopy [95], with a sedation potency 1.5-3.5 greater than that of diazepam [96]. It is effective after 1 - 3 minutes and reaches maximum effect after 3-4 minutes, although the duration of effect is between 15 and 80 minutes [97] depending on cofactors such as obesity, advanced age, and liver and kidney disease. The side-effect profile corresponds to that of diazepam but phlebitis is less common [98]. As sometimes also occurs with other benzodiazepines, midazolam administration can in rare cases lead to paradoxical reactions characterized by aggressiveness, hostility, and agitation. This phenomenon has been described in about $5 \%$ of patients receiving midazolam by short-lasting oral administration [99]. A study by Christe et al. [100] on sedation with midazolam of older patients (mean age $84 \pm 7$ years) undergoing EGD showed confusion in $14 \%$ of them even on the next day.

Midazolam is usually given as a bolus of $30-80 \mu \mathrm{g} / \mathrm{kg}$ body weight for gastroscopy $[6,7,100,101]$. For colonoscopy an initial bolus between 30 and $50 \mu \mathrm{g} / \mathrm{kg}$ is usually given. Subsequently, lower-dose boli are given until the desired sedation depth is reached $[64,102,103]$. The use of lower doses is recommended for patients older than 60 years $[79,100,103-105]$.

If sedation is the patient's preference, it is generally better to administer midazolam before the start of the examination rather than during it according to need $[106,107]$.

\subsubsection{Antagonistic effect of flumazenil on midazolam}

The effect of midazolam can be inhibited by using the benzodiazepine-specific antagonist flumazenil $[108,109]$. A study by Mora et al. [110] showed that flumazenil has a stronger antagonistic effect on benzodiazepine-induced sedation and amnesia than on respiratory depression. Neutralization of the midazolam-induced respiratory depression occurs 120 seconds after intravenous flumazenil administration [111].

The half-life of flumazenil is $0.7-1.3$ hours, and the average duration of the antagonizing effect is 1 hour. Since the effect of midazolam can last 80 minutes or longer, there is a danger of resedation, necessitating further administrations of flumazenil.
In a study by Andrews et al. [112], 50 patients who underwent gastroscopy with midazolam sedation received either flumazenil or placebo directly after the examination and again 30 minutes later. Those who had received flumazenil showed markedly improved memory, psychomotor function, and coordination after only 5 minutes ( $p<0.001)$. However, a re-evaluation of the same parameters 3.5 hours later showed no difference between the two groups. In contrast, the results of a study by Bartelsman et al. [113] of 69 patients who received flumazenil or placebo after midazolam administration for EGD demonstrated no resedation within 6 hours.

Routine administration of flumazenil at the end of an endoscopic procedure reduces recovery time [114], but so far no other benefits have been reported for either the patient or the endoscopist. Care should also be taken with patients taking carbamazepine or high doses of tricyclic antidepressants, or those suffering from chronic benzodiazepine abuse, as seizures or withdrawal symptoms can occur. For this reason, the routine use of flumazenil can not be recommended.

Patients who are judged nevertheless to need flumazenil should be observed for an appropriately longer period afterwards.

\subsubsection{Amnesia: diazepam versus midazolam}

Recommendation: Apart from occasional venous complications, diazepam has no disadvantages compared to midazolam. If benzodiazepines are used for sedation because of their stronger amnestic effect, midazolam should be preferred to diazepam because of its shorter half-life.

Recommendation grade B, evidence level 2a, consensus

Comments: Amnesia following the use of midazolam has been well studied [123] and in all studies has been shown to be significant. If amnesia is not desired, midazolam should not be used. An alternative benzodiazepine is diazepam [91,92]. The longer half-life of diazepam has not been reported in studies as a disadvantage compared to midazolam $[92,96,124]$. However, in some studies patient comfort was lower after diazepam than after midazolam. With respect to amnesia midazolam has the highest potency of all sedation methods.

\subsubsection{Propofol versus midazolam}

Recommendations: Data on efficacy, recovery, and complications suggest that propofol should be preferred to midazolam for sedation during gastrointestinal endoscopy. However, adjustments still need to be made taking into account the individual patient situation, the nature of the intervention, and the personal, personnel, equipment, and structural requirements indicated in this guideline. Recommendation grade $\mathrm{A}$, evidence level $2 \mathrm{~b}$, strong consensus

Comments: A summary of the existing randomized studies ( Table 10, Section 2.1.1) of patient acceptance or satisfaction shows that endoscopists judge propofol to be as good as benzodiazepines for sedation [56-58], or better [59,60].

Randomized studies suggest that propofol is preferable for EGD, colonoscopy, and ERCP [6-8,58-60,66-70,115]. The advantage of propofol sedation compared to benzodiazepines, for both the patient and the endoscopist, is a shorter time of onset [59], significantly better patient cooperation $[66,67,115]$ - especially in interventional endoscopy (such as ERCP) - and a shorter time for recovery $[6-8,58-60,66-70]$, including recovery of psychomotor function [8]. 
Two studies showed the superiority of propofol compared to midazolam/fentanyl with respect to recovery of neuropsychological/cognitive functions after ambulatory colonoscopy $[57,58]$. A randomized study by Riphaus et al. [8] on recovery of psychomotor function (assessed using a driving simulator) after sedation with propofol versus midazolam/pethidine (comparable with meperidine, mostly used in the United States and the United Kingdom) for EGD or colonoscopy also reported a significantly faster recovery time and quicker recovery of psychomotor function with propofol.

Another advantage of propofol compared to midazolam is the possibility of better-quality examinations. This was addressed in a study by Meining et al. [116] that compared propofol and midazolam sedation for EGD. The study showed that the quality of the depiction of the upper gastrointestinal tract (on video) was improved when patients were sedated with propofol. However, the endoscopic examination time was longer in the propofol than in the midazolam group [116].

Sedation with propofol makes colonoscopy examinations easier [117]; moderate sedation ("conscious sedation") is usually sufficient [118].

\subsubsection{Cardiorespiratory complications}

Comparative data on complications from 12 randomized studies were compiled in a meta-analysis by Qadeer et al. [119] that described the relative risk of sedation with propofol compared to benzodiazepines. The use of propofol for colonoscopy was associated with significantly fewer side effects. For other endoscopic interventions (EGD, ERCP) no significant difference was seen.

When propofol is used for ERCP there is in some cases a significantly higher risk of arterial hypotension compared to midazo$\mathrm{lam} /$ pethidine or meperidine $[58,66,115,120,121]$. There is also a tendency for oxygen saturation to drop below $90 \%$ with propofol sedation, although this is not statistically significant (see $\bullet$ Table 11).

In a recently published risk factor analysis by Wehrmann and Riphaus [122] in 9547 patients who received propofol sedation for interventional upper endoscopy over a period of 6 years (EGD, $\mathrm{n}=5374$, ERCP, $\mathrm{n}=3937$, EUS, $\mathrm{n}=236$ ), 3151 patients had monosedation with propofol and 6396 patients sedation with a combination of propofol and midazolam. A total of 135 severe complications were reported (1.4\%), leading to discontinuation of the intervention. Short-term mask ventilation was necessary in 40 patients $(0.4 \%)$ and endotracheal intubation in 9 patients $(0.09 \%)$. Eight patients needed additional observation in the intensive care unit $(0.3 \%)$ and four patients died, three of whom had side effects that could have been sedation-related (mortality rate $0.03 \%$ ). After multivariate analysis of the data, emergency interventions and a higher propofol dose were assessed as independent risk factors for cardiorespiratory complications [122].

\subsubsection{Other drugs as monotherapeutics}

\subsubsection{Introduction}

Other drugs are additional either sedating/hypnotic or analgesically active substances that do not fall into the usual substance classes. These include opiates and ketamine (as monotherapeutics), inhalation anesthetics, nonsteroidal anti-inflammatory drugs (NSAIDs) and neuroleptanalgesics. The few studies from the past that exist on these substances show at a moderate level of evidence that these drugs are in principle suitable for sedation. Evaluating the existing literature, the following points stand out:
1. The frequency of adverse side effects is much higher than for the usual sedation methods.

2. Some of these methods (such as neuroleptanalgesia) no longer have a role in modern anesthesia.

3. Scientific evidence is lacking for ketamine; specific side effects make these drugs unsuitable for use as a monosubstance. Only a few studies with small patient numbers exist on the use of ketamine in combination therapy (e.g., in combination with midazolam or propofol); they suggest a positive effect. However, further evaluation in randomized studies with larger patient numbers is required.

4. Inhalation anesthetics require special equipment, monitoring procedures, and standards of safety in the workplace. It is impossible to adhere to MAC values (maximum allowable concentrations) of the substances used because open inhalation systems are almost always used in endoscopy and routine protection of the airways (intubation, airtight laryngeal mask) is not usual.

5. On the basis of the current data, there is not enough evidence for the routine use of NSAIDs for endoscopic interventions.

Recommendation: Opiates, ketamines, inhalation anesthetics, and neuroleptanalgesics should not be used as monotherapeutics for sedation in endoscopy.

Recommendation grade B, evidence level 5 , consensus

\subsubsection{Opiates as monotherapeutics}

\subsection{Fentanyl}

\subsection{General}

Fentanyl is a lipophilic synthetic morphine derivative that is chemically related to pethidine. It is about 600 times more potent than pethidine and 100 times more potent than morphine. The effect starts only about 20 seconds after intravenous administration as the substance binds to specific opioid receptors in the brain and spinal cord. The maximum effect is expected after 6 minutes and the duration of effect is $20-30$ minutes. The initial dose is usually $50-100 \mu \mathrm{g}$. In older patients the dose should be reduced. The most common adverse side effect is respiratory depression, which because of the strong potency of the drug may be expected with a dose of as little as $0.1 \mathrm{mg}$ (for adults). In addition, thorax rigidity can occur, which can make it more difficult to ventilate the patient should that prove necessary. The effects on blood pressure and heart rate are fairly mild, usually causing a drop in these parameters due to vagal stimulation. Spasming of the smooth muscles of the bile duct and pancreas and spastic constipation can also occur. Nausea and vomiting under fentanyl is comparable to other opiates. Although fentanyl is usually used for general anesthesia (often in combination with other drugs) or for chronic pain (usually transdermally), there are few studies with small patient numbers on its use as an analgesic for endoscopy.

Comments: A prospective study on flexible sigmoidoscopy by Basu et al. [125] investigated 109 consecutive patients who received analgesia with a single bolus of fentanyl ( $50 \mu \mathrm{g})$ or no analgesia, according to patient preference. Significantly fewer of the 46 patients who received analgesia complained about moderate or severe pain than of the 63 who had no analgesia ( 9 vs. 26 , $P<0.05$ ). Patient satisfaction, especially with regard to repeat examinations using the same procedure, was significantly higher with analgesia than without $(P<0.01)$. An increase in cardiorespiratory complications with fentanyl was not reported. 
Another randomized study by Ishido et al. [126] of 84 patients undergoing EGD either under fentanyl sedation or without sedation showed that in addition to increasing patient tolerance analgesia also reduced the increase in heart rate induced by endoscopy. Apart from a minimal decrease in arterial oxygen content there was no significant difference in $\mathrm{O}_{2}$ saturation between the two groups.

\subsection{Remifentanil}

\subsection{General}

Currently, data on the routine use of remifentanil, a highly potent synthetically synthesized opioid with an extremely short half-life (2-3 min), are sparse. Notable points are an increased incidence of respiratory depression and that the drug should only be used as a continuous infusion for analgesia in spontaneously breathing patients. Its use is restricted to facilities that are completely equipped for monitoring and support of respiratory and cardiovascular functions (according to product information).

Comments: In a randomized study by Akcaboy et al. [127] 100 patients received a continuous infusion of remifentanil (bolus $0.5 \mu \mathrm{g} / \mathrm{kg}$, then $0.05 \mu \mathrm{g} / \mathrm{kg}$ per minute continuously) or propofol (bolus $0.5 \mathrm{mg} / \mathrm{kg}$, followed by $50 \mu \mathrm{g} / \mathrm{kg}$ per minute) for colonoscopy. The duration of the examination was longer and the oxygen saturation after bolus administration was lower after remifentanil than after propofol. Although the recovery time was shorter for remifentanil, the time to hospital discharge was comparable. Nausea and vomiting were observed much more frequently in the remifentanil group.

\subsubsection{Ketamines as monotherapeutics}

\subsection{General}

Ketamine is an intravenously or intramuscularly injectable general anesthetic with strong analgesic effect. It is mainly used as a "monoanesthetic" for short diagnostic and therapeutic interventions in children and for special situations in adults. After intravenous bolus administration ketamine has a rapid onset of action ( $<1 \mathrm{~min}$ ) and an effect duration of about 10-15 minutes [128]. It causes so-called dissociative anesthesia that is probably elicited by functional decoupling of the thalamoneocortical system from the limbic system. The analgesic effect starts at sub-dissociative doses and lasts longer than the anesthesia. The sedative and hypnotic properties of ketamine, however, are much less pronounced. Muscle tone is maintained or increased under ketamine anesthesia so the protective reflexes are not affected. The spasm threshold is not reduced. With spontaneous breathing, intracranial pressure rises. Because of its sympathicotonic effect, ketamine leads to a rise in blood pressure and heart rate, which in turn causes an increase in myocardial oxygen consumption and concomitantly increased coronary perfusion. Ketamine displays a negative inotropic and antiarrhythmic effect on the heart itself. As a result of the opposing influences, the peripheral resistance barely changes. Moderate hyperventilation is observed after ketamine administration. It has a relaxing effect on the bronchial muscles. Contraindications for the use of ketamine include insufficiently treated or untreated arterial hypertension (systolic/ diastolic blood pressure above $180 / 100 \mathrm{mmHg}$ at rest) and patients for whom a rise in blood pressure would constitute a substantial risk (e.g., history of cerebrovascular insult).

Relative contraindications include unstable angina pectoris or myocardial infarction in the preceding 6 months. Since in general the pharyngeal reflexes are maintained, mechanical irritation of the pharynx should be avoided when ketamine is employed as a monoanesthetic unless additional muscle relaxants are used. For interventions in the pharynx, larynx, and bronchial tree especially, therefore, muscle relaxation with ventilation may be necessary. One adverse side effect is the frequent occurrence of hallucinations, nightmares, and delirious states in about $10 \%-30 \%$ of cases. These reactions can be reduced by giving midazolam in addition [129].

Comments: For the reasons given above, ketamine is not recommended as a routine monotherapeutic for endoscopic examinations.

Most studies on the use of ketamine relate to its use in combination therapies - mainly with midazolam - for endoscopic interventions in children $[130,131]$. It was shown that adequate sedation can be achieved without cardiorespiratory complications.

Although the data on the use of ketamine in adults are limited, there are indications that adjunctive use of ketamine, in combination with midazolam, can be beneficial for certain patients (all contraindications being observed). A double-blind, placebo-controlled study by Rosing et al. [132] that compared midazolam/ placebo with midazolam/ketamine for colonoscopy in 129 patients showed that patients receiving the combination therapy needed fewer repeat injections ( $40 \%$ vs. $27 \%$ ), had better sedation and analgesia, and were more willing to agree to undergo another similar procedure.

A randomized study by Ong et al. [133] that compared ketamine combination sedation (ketamine plus midazolam, pentazocine, propofol) with propofol monosedation for ERCP demonstrated that especially in younger patients the benefit of the combination sedation was better patient tolerance. However, patient satisfaction was similar in both groups. In addition, hypoxia occurred more frequently when the combination therapy was used.

\subsubsection{Inhalation anesthetics as monotherapeutics}

\subsection{Dinitrogen monoxide (nitrous oxide, laughing gas)}

\subsection{General}

Nitrous oxide $\left(\mathrm{N}_{2} \mathrm{O}\right)$, so-called "laughing gas," is a stable, slow-reacting, colorless, and odorless gas. It is strongly analgesic and mildly narcotic. Voluntary movement is not influenced. Its advantage is its rapid onset of effect and short recovery time. Mixed with oxygen, it is normally used to initiate anesthesia, for combination anesthesia, or for analgesia for women giving birth in hospital.

Nitrous oxide is inhaled. It must always be administered after vaporization (transition to gas phase) using suitable inhalation or anesthesia equipment. Although it normally affects the circulation only slightly, a drop in blood pressure, decreased stroke volume, and increased pulmonary vascular resistance can occur, as can dilatation of the cerebral vessels followed by a rise in intracranial pressure. Possible adverse side effects are nausea and vomiting. The occurrence of euphoria, dreams, and fantasies has been described. If the dose is too high, hypoxia, circulatory depression, agitation, or somnolence and even unconsciousness may occur.

Comments: A randomized study by Saunders et al. [134] comparing patient-controlled nitrous oxide inhalation with intravenous midazolam/pethidine administration for colonoscopy showed that in addition to a significantly faster recovery time after nitrous oxide inhalation ( 32 vs. $60 \mathrm{~min}, P=0.01$ ), the drop in blood pressure and oxygen saturation was also smaller. However, headache often occurred with nitrous oxide inhalation.

In another study by Forbes et al. [135] patients undergoing colonoscopy randomly received either nitrous oxide or midazolam/ 
meperidine (average dose: $4.7 \mathrm{mg}$ and $55 \mathrm{mg}$ ). Nitrous oxide was less effective, patients more frequently recalled pain during the examination $(P<0.001)$, and were significantly less satisfied with the intervention $(P<0.01)$. However, the recovery time was significantly shorter than with midazolam/meperidine (30 vs. $60 \mathrm{~min}, P=0.0001$ ).

In a study by Maleskar et al. [136] that was recently published as an abstract, 100 patients randomly received either nitrous oxide or midazolam/fentanyl for colonoscopy. In contrast to the study by Forbes et al., patient satisfaction was better under nitrous oxide, the patients reported less pain, and the time to hospital discharge was significantly shorter (26 vs. $44 \mathrm{~min}, P=0.004$ ).

\subsubsection{Nonsteroidal anti-inflammatory drugs}

\subsection{Ketorolac trometamol}

\subsection{General}

Ketorolac trometamol is a NSAID with analgesic effect and rapid onset of action within minutes after intravenous injection. Its mechanism of action is based on inhibition of prostaglandin biosynthesis. It is usually used for the treatment of acute pain. In Germany the substance is only available for administration as eye drops.

Like other NSAIDs, ketorolac trometamol can cause gastrointestinal irritation, ulcers, bleeding, or perforation with or without preceding symptoms, and for this reason it should not be given to patients with known diseases of the gastrointestinal tract. Other adverse side effects are fluid retention and edema, so care should be taken with patients with cardiac decompensation and hypertension. Headache, numbness, drowsiness, sweating, and dizziness also often occur.

Comments: A randomized, double-blind, placebo-controlled study by Mui et al. [137] investigated the effect of intravenously administered ketorolac trometamol $(60 \mathrm{mg})$ as premedication 30 minutes before the start of patient-controlled sedation (with propofol/alfentanil) for colonoscopy in a total of 140 patients.

The pain scores as rated by both patients and endoscopists were significantly lower in the ketorolac group than in the control group (3.99 vs. $5.28, P=0.006$ and 80.0 vs. $57.1 \%, P=0.004$ ). There were no significant differences between the two groups with respect to drug dose, patient satisfaction, and hemodynamic changes.

Further data that demonstrate actual superiority of NSAIDs over the current usual sedation regimens are lacking and therefore no overall recommendation can be made for the routine use of NSAIDs.

\subsection{Combination therapies}

\subsubsection{General}

Combination therapies are usually comprised of a sedative and an analgesic or a combination of different sedatives. While monosedation with benzodiazepines such as diazepam or midazolam [138-141] reduces stress-induced cardiovascular complications (e.g., myocardial ischemia, rise in rate-pressure product), combination with an opiate [142-144] or hypnotic such as propofol $[70,145]$ also leads to increased patient acceptance.

By combining different substances, the required dose can be reduced [146] and the recovery time shortened $[59,57,143,146]$. However, it should also be remembered that, compared to monotherapy, combination therapy can often lead to a fall in blood pressure and oxygen saturation [147-149] (see also Section 2.3.3).

\subsubsection{Specific combinations}

\subsubsection{Combination of sedative plus opiate}

Recommendations: The combination of a sedative with an analgesic leads to better patient acceptance and at the same time a lower dose of sedative. Combination therapies with opiates can be a good choice for painful interventions provided that the structural and personnel requirements are met (for the appropriate requirements see Section 3).

Recommendation grade 0 , evidence level $1 \mathrm{~b}$, consensus

Comments: A study by Milligan et al. [143] comparing a combination of alfentanil/midazolam with midazolam alone for upper intestinoscopy showed an improvement in examination conditions for the endoscopist, increased patient acceptance, and a shorter recovery time.

Another randomized, double-blind study by Radaelli et al. [144] that compared midazolam to midazolam/meperidine for colonoscopy in 253 patients reported significantly less pain and a higher rate of willingness to repeat the intervention under combination therapy. The recovery time and the fall in oxygen saturation were comparable in both study groups.

In a randomized, controlled study by VanNatta et al. [150] 200 patients undergoing colonoscopy were given propofol alone to reach deep sedation or a combination treatment with propofol/ fentanyl, propofol/midazolam, or propofol/midazolam/fentanyl to reach moderate sedation. Recovery time, patient satisfaction, and vital signs were compared. Patients with propofol sedation alone needed significantly higher doses and showed deeper sedation stages than those given the other combination treatments $(p<0.001)$. The time to discharge was significantly shorter after the combination treatments than after propofol alone (median $13.0-14.7 \mathrm{~min}$ versus $18.1 \mathrm{~min}, P<0.01$ ). Vital signs and patient satisfaction were comparable in all study groups.

\subsubsection{Combination of sedative plus propofol}

Recommendation: Combination with various sedatives (e.g., midazolam plus propofol) leads to the same acceptance/tolerance for the procedure with probably the need for a lower dose of propofol. Combination therapy with midazolam/propofol can be a good choice so long as the relevant structural and personal requirements are met.

Recommendation grade $\mathrm{B}$, evidence level $1 \mathrm{~b}$, strong consensus

Comment: A study by Cordruwisch et al. [151] of 64 patients undergoing two consecutive, long (> $30 \mathrm{~min}$ ) endoscopic examinations, who initially received propofol and then a combination of midazolam and propofol, showed that the advantage of the combination sedation was the significantly lower propofol dose required (reported as 59\% compared to monotherapy). However, the postinterventional recovery time was twice as long for the combination regimen ( 4 vs. $8 \mathrm{~min}$ ).

A study by Seifert et al. [146] of 239 consecutive patients undergoing therapeutic endoscopy (EGD and endoscopic ultrasonography) also demonstrated that the combination of propofol and midazolam led to a lower dose of propofol compared to monotherapy $(0.20 \pm 0.09 \mathrm{mg} / \mathrm{min}$ per kilogram body weight vs. 0.25 $\pm 0.13 \mathrm{mg} / \mathrm{min}$ per kilogram, respectively, $P<0.01$ ), with otherwise comparable effectivity. However, the combination regimen was also associated with a longer recovery time ( $25 \pm 8 \mathrm{~min}$ vs. $19 \pm 7$ min, $P<0.05$ ). Similar dose reduction with the combination of propofol and midazolam was reported in the abovementioned study by VanNatta et al. [150]. However, the postinterven- 
tional recovery times were shorter in the combination therapy arm (13.0-14.7 min vs. $18.1 \mathrm{~min}, P<0.01)$ than with propofol monotherapy.

\subsubsection{Combination of sedative plus spasmolytic}

Recommendation: The combination of spasmolytics with sedatives increases the rate of cardiovascular side effects and reduces both patient satisfaction and the endoscopist's evaluation of the examination. The use of spasmolytics in sedation for endoscopy should therefore be carefully considered.

Recommendation grade A, evidence level $1 \mathrm{~b}$, strong consensus

Comment: A prospective, double-blind, placebo-controlled study by Mui et al. [152] investigated the use of the spasmolytic hyoscine $\mathrm{N}$-butylbromide (Buscopan) for premedication in patientcontrolled sedation with propofol/alfentanil for colonoscopy. The study demonstrated a longer cecum intubation time, significantly lower endoscopist satisfaction, a significantly higher dose of sedative/analgesic, and significant hemodynamic instability.

\subsubsection{Side effects of combination therapy}

\subsubsection{General}

Even if the recommended dose reduction for combination therapy is followed, respiratory function is compromised more frequently than under monotherapy [147-149]. Based on the existing studies it cannot be shown whether life-threatening situations occur more often under combination therapy.

Comments: Rembacken et al. [149] investigated the role of pethidine for colonoscopy. In this randomized, double-blind, placebocontrolled study, 71 patients were sedated with diazepam or diazepam plus pethidine. Patient satisfaction was similar in both groups, but the endoscopists preferred the combination therapy because of better patient tolerance. However, with combination therapy oxygen saturation dropped twice as often as with diazepam monotherapy $(P=0.008)$.

In another study by DiPalma et al. [147] on the role of alfentanil for colonoscopy, 35 patients randomly received either a combination of alfentanil/midazolam or midazolam alone. A fall in oxygen saturation resulting in a need for oxygen administration occurred more frequently than with the monotherapy. Patient tolerance, patient satisfaction, recovery time, and blood pressure were comparable in both groups.

A randomized, double-blind study by Moerman et al. [148] investigated the addition of remifentanil to sedation with propofol in 50 relatively healthy patients (ASA grades I and II) undergoing colonoscopy. Blood pressure and oxygen saturation dropped significantly more often in the remifentanil/propofol group. Although the addition of remifentanil allowed the dose of propofol to be reduced, recovery time was significantly shorter $(P<0.01)$ and patientsatisfaction significantly higher $(P<0.01)$ with propofolalone.

\subsubsection{Monitoring/structure quality}

Recommendation: Because of drug interactions, the dose of the drug in use should be adjusted in combination therapies. In addition, as the risk is difficult to calculate, care must be taken that adequate monitoring is available and that another physician experienced in cardiopulmonary resuscitation and ventilation (including intubation and assisted ventilation) can be called on to intervene immediately if required (also see Section 3).

Recommendation grade $\mathrm{A}$, evidence level $1 \mathrm{~b}$, consensus

\subsection{Effect of co-morbidity}

\subsubsection{General}

Co-morbidity basically means a higher ASA classification and concomitant diseases (including ASA grades II and III) that are associated with a higher incidence of side effects $[71,153,154]$. Older patients and patients with pre-existing coronary or pulmonary diseases in particular are at higher risk of complications during endoscopy with sedation $[71,138,155]$.

Hepatobiliary diseases in which drug elimination is reduced, or age-related slower metabolism, can also lead to potentiation of side effects [156,157].

A multiplicity of physiological processes contribute to increased sensitivity towards the various drug substances, leading to a correspondingly increased sedation risk [158]. With advancing age arterial oxygen saturation declines, with or without additional oxygen administration. The cardiorespiratory reaction to hypoxemia or hypercapnia is also reduced and delayed. Narcotics and other centrally acting substances lead to increased respiratory depression and more frequent occurrence of transient apnea. Age-related diseases and rapid or excessive doses contribute more strongly to such cardiorespiratory complications than age per se [158].

\subsubsection{High-risk patients}

Recommendation: Patients with a higher ASA grade and/or older patients are at higher risk of sedation-related side effects (cardiorespiratory depression). The dose of the sedative used should be adjusted accordingly.

Recommendation grade B, evidence level 2b, strong consensus

\subsubsection{Substance type}

Recommendation: Sedation using propofol as a substitute for benzodiazepines can be considered for older patients and patients with cardiorespiratory or liver disease. Theoretically, a transient exacerbation of, e.g., hepatic encephalopathy, which has been demonstrated for benzodiazepines, is not expected to occur with propofol. Recommendation grade 0 , evidence level $2 \mathrm{~b}$, consensus

Comments: In accordance with the modified recommendations of the American Society of Gastroenterology for older patients undergoing gastrointestinal endoscopy [159], fewer substances given more slowly and at a lower cumulative dose should be administered $[159,160]$.

Like young patients, older patients are usually sedated with midazolam and/or other opioids or narcotics. Since benzodiazepines increase the risk of hypoxemia in older patients, overweight patients, and anemic patients, a dose reduction is also recommended here [161]. This group of substances also carries a higher risk of postinterventional hypoxemia, especially in older patients $[121,162]$. In addition, in patients with liver cirrhosis benzodiazepines lead to transient exacerbation of hepatic encephalopathy $[156,157,163,164]$, which has not been seen with propofol monotherapy [164].

In a randomized study by Riphaus et al. [164], 60 patients with known liver cirrhosis and portal hypertension were sedated in a ratio of $2: 1$ in a randomized fashion with either propofol or midazolam for gastroscopy with interventional intent (variceal ligation). Before and 2 hours after the examination all patients took a number connection test (ZVT-A) and a portosystemic encephalopathy syndrome test (PSE), the latter made up of four additional individual test components. The evaluation was based on an overall score from these tests. Twenty patients without liver cir- 
rhosis who did not undergo gastroscopy were the control group. Recovery time and the recovery score were also determined. Compared to sedation with midazolam, patients sedated with propofol had a significantly shorter recovery time (18.4 $\pm 6.7 \mathrm{~min}$ vs. $7.8 \pm 2.9 \mathrm{~min}$, respectively). Propofol also affected the PSE score less than midazolam, the use of which led to transient exacerbation of the existing subclinical hepatic encephalopathy. Hence, sedation with propofol tends not to cause exacerbation of subclinical hepatic encephalopathy in patients with liver cirrhosis and is therefore an alternative sedative for use in these patients.

Since propofol has a limited therapeutic range, it can lead to more cardiorespiratory complications in older high-risk patients than in younger patients [71,165].

Low initial doses of propofol (in general half the recommended dose for adults), slow, gradual titration, and careful monitoring are recommended for sedation of older patients $[166,167]$. It has been shown that, used with due care, propofol can be safely employed for sedation in this age group $[121,165]$.

A cohort study by Vargo et al. [153] studied risk factors for cardiopulmonary events during propofol sedation for upper and lower intestinoscopy. The overall risk of a cardiopulmonary event during 528 gastroscopies and 1683 colonoscopies was 11.7 per 1000 cases. A higher risk was found in patients with increasing ASA grade who were undergoing colonoscopy.

A study by Heuss et al. [165] on the safety of propofol sedation during endoscopic examinations (gastroscopy and colonoscopy) in high-risk patients (ASA grades III and IV) compared to patients in ASA grades I and II also showed that the high-risk group were at higher risk of a short-term but relevant drop in oxygen saturation below $90 \%$ ( $3.6 \%$ vs. $1.7 \%$ for ASA grades I and II, $P=0.036$ ). Short-term mask ventilation was necessary in four cases (ASA grades III and IV) compared to one case (ASA grades I and II). The dose required for adequate sedation in high-risk patients was $10 \%-20 \%$ lower than that required for patients classified as ASA grades I and II. Accordingly, the authors stipulated particularly careful monitoring in older high-risk patients.

In a randomized, controlled study by Riphaus et al. [121] 150 patients over the age of 80 years were sedated with either propofol or midazolam and pethidine before undergoing ERCP. Clinically relevant cardiorespiratory changes were not observed more frequently under propofol than under midazolam/pethidine. The recovery time was significantly shorter with propofol (22 $\pm 7 \mathrm{~min}$ vs. $31 \pm 8 \mathrm{~min}$ for midazolam/pethidine, $P<0.01$ ). Furthermore, a drop in oxygen saturation below $90 \%$ occurred significantly less frequently during postinterventional monitoring ( $12 \%$ vs. $26 \%$ for midazolam/pethidine, $P<0.01$ ).

It must be remembered that certain personnel requirements obtain (see Section 3.3) in respect of multimorbid patients and patients with an increased risk profile.

\subsection{Music during endoscopy}

Recommendation: The use of relaxing music has a positive effect on patient acceptance of colonoscopy and results in a reduction of the average dose of propofol or midazolam.

Recommendation grade $\mathrm{B}$, evidence level $2 \mathrm{~b}$, strong consensus

Comment: A prospective randomized study by Harikumar et al. [166] investigated the effect of relaxing music on the dose of patient-controlled sedation with propofol in patients undergoing colonoscopy. Music significantly reduced the dose of propofol and midazolam and improved patient acceptance.
A recent meta-analysis by Rudin et al. [167] evaluated six randomized controlled studies with a total of 641 patients. In three studies endoscopy was done with music alone. This reduced the patients' fear in comparison to the control group by $8.6 \%$ $(P=0.004)$. In the remaining three studies patients received music therapy in addition to drug therapy (midazolam, pethidine, or propofol/alfentanil). This significantly reduced the need for analgesics by $29.7 \%(P=0.001)$ and the need for sedatives by $15 \%$ $(P=0.055)$.

\section{Structure quality: personal/personnel/equipment requirements \\ $\nabla$}

Since there are currently no prospective studies on the topic complex of structure quality, almost all recommendations are based on previous guidelines and recommendations [168-186].

\section{Introduction}

The endoscopic examination and/or treatment and the sedation procedure are distinct medical interventions. If one physician performs the diagnostic or therapeutic intervention and at the same time also carries out the sedation, he or she takes on full responsibility not just for the intervention but also for the sedation and/or analgesia, including monitoring and, if required, restoration of vital functions.

Special theoretical and practical knowledge of sedation and/or analgesia is necessary not just for physicians, but also for supporting nurses. A physician cannot perform the invasive intervention and at the same time be monitoring the sedation and/or analgesia procedures.

A specially trained person (usually a physician) other than the physician performing the intervention should be responsible for the sedation procedure and the monitoring of vital functions.

The person who is monitoring sedation should not have any other duties at this time. The decision - and the responsibility for the decision - as to whether in certain cases (e.g. deep sedation or general anesthesia induced by propofol or combination therapies) this person can be not a physician but another qualified, specially trained person (a nurse), lies with the physician doing the diagnostic or therapeutic intervention, and must take into account the structure of the workplace, the patient's condition, and the complexity of the intervention.

The examining physician (endoscopist) must ensure that such nurses are sufficiently qualified and capable of carrying out their tasks appropriately.

The problem of organization/transfer of liability rests on general legal principles based on civil, criminal, and occupational law. The detailed manufacturer's information for the drug used, especially in respect of structure quality (e.g., equipment and personnel requirements) must be followed.

\subsection{Personal requirements}

Recommendation: The physician who performs and is responsible for the sedation should be experienced in intensive care medicine. He or she should be trained and proficient in the use of sedatives. This includes knowledge, recognition, and treatment of expected side effects including cardiopulmonary resuscitation, freeing and maintaining open airways, intubation, and assisted ventilation. Recommendation grade A, evidence level 4 , strong consensus 


\begin{tabular}{|c|c|c|c|c|c|}
\hline Author & $\mathbf{N}$ & Procedures & Assisted ventilation, $\%$ & Hypotension*, \% & \multirow{6}{*}{$\begin{array}{l}\text { Table } 12 \text { Observed cardiore- } \\
\text { spiratory complication rate } \\
\text { during NAPS procedures. }\end{array}$} \\
\hline Rex et al. [16] & 2000 & EGD and colonoscopy & 0.2 & 0 & \\
\hline Heuss et al. [14] & 2547 & EGD and colonoscopy & 0.002 & 0.08 & \\
\hline Sieg [189] & 3641 & EGD and colonoscopy & 0.14 & 0.3 & \\
\hline Rex et al. [15] & 36743 & EGD and colonoscopy & 0.2 & n.i. & \\
\hline Tohda et al. [18] & 27500 & EGD and colonoscopy & 0 & 2.0 & \\
\hline
\end{tabular}

Comment: As in the guidelines of other professional associations $[10,11,21,22,35,37,41,166,187]$, personal prerequisites for carrying out sedation analgesia include knowing how to deal with an emergency situation by correcting circulation problems and being proficient in endotracheal intubation.

\subsection{Education and training courses}

Recommendation: As part of quality assurance, physicians and nursing staff should receive special training in sedation.

Recommendation grade A, evidence level 4, strong consensus

Comments: So far, only isolated special training guidelines exist on premedication and management of emergency situations. These show that specific training, including in the form of simulation courses, improves physicians' confidence [188].

A much more extensive training program for nurses was the subject of several studies using propofol $[14,73]$.

\subsection{Personnel requirements}

\subsubsection{Education requirements}

Recommendation: The qualification of physicians and nurses involved in sedation, monitoring, and follow-up should be ensured by periodical participation in structured further education curricula. In addition to theoretical knowledge, these curricula transmit practical competencies including complications management (e.g., in simulation training). In general, it is preferable for the whole endoscopy team (doctors and nurses) to do the training together. Recommendation grade A, evidence level 5, strong consensus

\subsubsection{Sedation monitoring}

Recommendation: The physician endoscopist is not usually able to pay adequate attention to the patient's vital functions during the procedure. For this reason, for every endoscopy under sedation it is necessary to have one person present in addition to the endoscopist and the assisting nurse, who is not involved in the intervention and who can fulfill this task reliably. This qualified person should be able to show proof of special training and experience in monitoring patients receiving sedatives, hypnotics, and/or analgesics. In all cases when a patient has an increased risk, or when a long, complex intervention is expected, a second physician qualified in resuscitation and intensive care should be present whose only task is the sedation and monitoring of the patient.

Recommendation grade A, evidence level 5, strong consensus Comment: The guideline of the German Society for Anesthesiology and Intensive Care Medicine (Deutsche Gesellschaft für Anästhesiologie und Intensivmedizin, DGAI) [10] states: "Since the examiner is usually unable to watch the patient's vital functions with sufficient care while doing an endoscopy, it is necessary for a second, specially trained and qualified person to reliably take over the patient monitoring."
Recommendation: The management of endoscopic sedation should take into account the patient's health, the invasiveness of the intervention, and the type of sedation being used.

Recommendation grade A, evidence level 5, strong consensus

\subsubsection{Carrying out the sedation}

3.3.3.1 Requirements for nurse-administered propofol sedation

Recommendation: For simple endoscopic examinations and in low-risk patients, sedation should be induced by a properly qualified physician and can then be monitored by an experienced person with appropriate training. The person must not have any other tasks while monitoring the sedation. Propofol may be administered, on a physician's instruction, by a properly trained and experienced person who has this as his or her sole task.

Recommendation grade A, evidence level 1b, strong consensus

Comments: Nurse-administered propofol sedation (NAPS) is safe and efficient under certain conditions [14-17,73] for patients in ASA grades I- III (see Table 12).

NAPS should not be done for ASA grade IV - V patients [14$17,73]$. NAPS should be performed by a person who is appropriately trained and has this as his or her sole task.

\subsubsection{Restrictions on NAPS}

Recommendation: For patients with an increased risk profile (see Section 1.4 on risk assessment), or for long, complex therapeutic interventions that require deep sedation and are thus associated with a higher sedation risk, a second physician who is experienced in intensive care medicine should perform the sedation.

Recommendation grade A, evidence level 5, strong consensus

\subsubsection{Monitoring after the endoscopic procedure}

Recommendation: Patients should continue to be monitored with respect to their sedation after the examination is over.

Recommendation grade A, evidence level 5, strong consensus

Comment: Postinterventional monitoring is necessary to detect any sequelae of sedation. The duration of the postinterventional monitoring phase depends on the expected risk [20]. The duration of action and the half-life of the substance used should be taken into account.

Close monitoring of the patient by qualified personnel should be continued, irrespective of the substance used, and using a pulse oximeter if thought desirable, until the patient has completely recovered. Patients can be released from the monitoring area when their vital signs are stable and they are oriented [10].

Recommendation: Patient monitoring during the recovery phase should be done by appropriately trained and qualified personnel. Recommendation grade A, evidence level 5, strong consensus 
Comment: The monitoring person must always be present in the recovery area or have the recovery unit in view. He or she may, however, e.g. use the telephone or file reports. For safety reasons, patients who have already woken up should stay in the recovery area until their release. This prevents patients from leaving the area on their own while still under the influence of sedation [see verdict of the German Supreme Court (Bundesgerichtshof), reference no. VI ZR 265/02].

\subsection{Facilities requirements}

Recommendation: Sedation should only be carried out in a place that is adequately equipped for monitoring and support of respiratory and cardiovascular function. There should be an additional, separate recovery area.

Recommendation grade A, evidence level 5, strong consensus

Comment: According to the DGAI guideline [10]: "the location and the equipment of the treatment and monitoring area should be geared to the needs of patients with relevant concomitant diseases (ASA grade III and higher). The recovery unit should be equipped for monitoring (pulse oximetry, blood pressure, ECG), with drugs, oxygen supply, and a pipeline outlet for suction, together with all the auxiliary material and equipment needed for resuscitation. In case of severe complications, suitable transport to a qualified treatment unit (e.g., intensive care unit) must be possible (e.g., an elevator large enough to take a bed)." Currently, no evidence-based data relating to the current recommendations and standards are available.

A verdict of the German Supreme Court (reference no. VI ZR 265 / 02 ) criticized the seating of patients in the hall outside the treatment room after endoscopy under sedation. The recovery area must be defined as such and the patients must be under constant observation.

\subsection{Equipment}

\subsubsection{Clinical monitoring/standard monitoring}

Recommendation: Necessary monitoring measures include pulse oximetry and blood pressure measurement (especially for sedation with propofol). An ECG recording should be done for patients with severe heart disease.

Recommendation grade A, evidence level 5, strong consensus

Comment: The person in charge of monitoring checks breathing clinically by observation, palpation of thorax and abdominal wall movement, and possibly palpation of the expiratory airstream. The endoscopy personnel must have appropriate emergency training and must be proficient in cardiopulmonary resuscitation.

According to the recommendations of various national and international professional associations, pulse oximetry is required for monitoring after all examinations [9-11,19,22,37]. For sedated patients and high-risk patients, continuous blood pressure monitoring and an ECG lead are also demanded.

In addition to clinical monitoring, pulse oximetry is required for sedation today (especially since the introduction of quality assurance agreements for colonoscopy in Germany). Oxygen saturation and heart rate are measured continuously. According to a survey in 2003, in Switzerland more than 95\% of endoscopies were monitored by pulse oximetry [190]. In international studies at European centers in 2006, $77 \%$ of the colonoscopies were monitored with pulse oximetry [191]. A recent survey in Germany showed that pulse oximetry is used in $97 \%$ of examinations
[5]. For propofol sedation, blood pressure must also be monitored. The best monitoring devices show oxygen saturation, heart rate, and blood pressure on one screen that can be placed right next to the endoscopy monitor, so that the endoscopist can watch both. Documentation of the measurement parameters is desirable.

\subsubsection{Extended monitoring}

3.5.2.1 Capnography

Recommendation: Capnography is not mandatory for gastrointestinal endoscopy. It can be used for early detection of apnea.

Recommendation grade 0 , evidence level $2 \mathrm{~b}$, strong consensus

Comment: During capnography the concentration of $\mathrm{CO}_{2}$ in the breath is recorded using a nose mask. Breathing can be graphically displayed. Apnea can be diagnosed much earlier using this method than with pulse oximetry; this is especially important in pediatric interventions [192-194].

In a prospective study by Vargo et al. [195] of 49 adults undergoing gastroscopy with therapeutic intent, twice as many apnea episodes were diagnosed by capnography than by pulse oximetry or clinical observation. In another prospective study by Anderson et al. [192] of 163 children, none of the apnea episodes that occurred in $24 \%$ of the endoscopic procedures was diagnosed by pulse oximetry or clinical observation alone.

In a retrospective study by Koniaris et al. [196], 4846 patients were monitored without and 600 patients with capnography during endoscopy. In the patient group not monitored with capnography there was a tendency toward oversedation, especially in older patients and those undergoing long examinations, although it was not significant. In the capnography group no case of oversedation was reported.

No data are available regarding clinical endpoints (e.g., severe hypoventilation with clinical consequences) when capnography is not used in gastrointestinal endoscopy.

On the basis of currently available data, routine use of capnography generally cannot be recommended.

\subsubsection{EEG monitoring}

Recommendation: The benefit of EEG monitoring with respect to relevant parameters in gastrointestinal endoscopy has not been demonstrated.

Recommendation grade 0 , evidence level $1 \mathrm{~b}$, strong consensus

Comment: Bispectral monitoring is used to evaluate sedation depth in intensive care medicine and in surgical patients. A pilot study described bispectral monitoring as part of a closed monitoring cycle for the continuous infusion of propofol in 16 patients sedated for colonoscopy [84]. In another randomized controlled study by Wehrmann et al. [115] a significant reduction of the propofol dose was shown when another EEG monitoring technique was used for ERCP. Bispectral monitoring cannot be recommended for gastrointestinal endoscopy, especially for short examinations such as colonoscopy, because according to existing study data $[197,198]$ no reduction in propofol dose was achieved, and therefore neither the recovery time shortened. 


\section{Informed consent/prerequisites for performance of sedation/preservation of vital functions/clinical monitoring/emergency management \\ $\nabla$}

4.1 Informed consent of the patient

Recommendation: When patients are being given information about the endoscopy, they should also be told about side effects of sedation, especially retrograde amnesia and the possibility of restricted psychomotor capability after the sedation.

Recommendation grade A, evidence level 5 , strong consensus

\subsubsection{General and legal aspects}

The adjudication on medical interventions, the physician's duty to inform, and patient information is very complex.

According to permanent adjudication of the German Federal Supreme Court, every medical intervention constitutes a personal injury offense according to paragraph $223 \mathrm{ff}$. StGB, 823 I BGB. Medical interventions include not just the performance of diagnostic procedures but also of therapeutic measures such as operations or the administration of drugs [199].

The consent ("informed consent") that is necessary for these procedures is only valid if the patients have been given sufficient information and are competent to exercise their right to self-determination.

If patients are not competent to give their consent (e.g., children, severely mentally retarded persons), the physician must give the information to their representative (guardian, agent for health care matters, or other person responsible) $[200,201]$.

To be competent to give their consent, patients must also be able to understand the implications of the intervention. Aside from the legal background, a well-performed consent procedure with information and explanation increases patient satisfaction [37]. Patients should receive the information even if they have already undergone a similar endoscopic intervention and they claim to have been given plenty of information the first time. Many patients are not good judges of their own level of information and understanding. Moreover, information received earlier may have been forgotten or details remain misunderstood.

\subsubsection{Informing person}

Recommendation: A competent and experienced physician should provide information about the procedure to the patient in a form he or she can understand.

Recommendation grade A, evidence level 5 , strong consensus

Comments: The physician must be competent and experienced in sedation. Informing the patient, who is usually uneducated in medicine, must be done gently and comprehensibly. It is important that the patient understands the impact and implications of the intervention, and the physician must make quite sure that the patient does have this understanding. Delegation, e.g. to a nurse, is not permissible by law in Germany.

\subsubsection{Informed consent procedure}

Recommendation: The foundation of the consent procedure should be a discussion between the physician and patient. The content and range of the discussion should be documented. The patient should receive the information in good time.

Recommendation grade A, evidence level 5 , strong consensus
Comments: The information about and discussion of the proposed procedure must be conducted in a patient-centered manner, i.e., dependent on the patient's ability to comprehend and on how much information he or she wants. Standardized patient information forms can be used in addition to help convey the information and for documentation purposes, but they are not a substitute for the personal discussion.

Written documentation is essential, because according to civil law physicians have to be able to prove that the consent procedure was followed correctly [199].

The extent of the consent procedure is in inverse proportion to the urgency of the intervention.

Patients should not be told that they may waive their right to information, and should certainly not be urged to do so. However, if they refuse the information of their own accord, this refusal should be documented and signed by the patient [201,202].

The importance of the patient's right to decide dictates that they should have enough time to give their consent before the procedure, and this involves an informed consent process that starts early enough for their decision to be made without time pressure. The right time for the information interview depends on the individual situation. Even in an emergency, responsive patients should have as much explained to them as time permits before giving their consent [202].

Altogether, the information procedure should proceed as soon as possible; ideally it should be started when the appointment for the endoscopic intervention is made [202].

\subsubsection{Content of the patient information interview}

Recommendation: The discussion should include information on the preparation for sedation, various sedation methods, and their possible complications. It should also include making the patient aware that it is possible to carry out the intervention without sedation.

Recommendation grade A, evidence level 5 , strong consensus

Comments: In almost all interventions, adverse effects of sedation are responsible for at least $50 \%$ of complications [203]. Complications of sedation (aspiration, arterial hypotension, bradycardia, apnea, etc.) are therefore typical complications and must be discussed with the patient in detail. The patient should be told about the typical sedation risks irrespective of complication rates. Severe atypical risks must also be discussed. At the same time the discussion should be gentle; the patient must not be frightened with exaggerated risk information.

The physician should advise the patient on the "if and how" of sedation. In addition to sex and age, it is wise to take into account the patient's level of anxiety/fear when setting the sedation dose, because these three factors have been shown to predict the patient's cooperation during the intervention, and on his or her satisfaction afterwards $[105,204,205]$. On the whole, younger and more anxious patients and women should tend to be advised to choose sedation $[20,27,30,48,105]$.

However, as sedation usually seems necessary to avoid unwanted involuntary patient movement, especially during long examinations and difficult interventions (e.g., ERCP, difficult polypectomy), this too should be explained to the patient $[11,23,91,206]$. If the patient suffers injury after withholding consent to a necessary intervention as a result of an information interview that was too "tough," the physician is responsible [207].

Sedation can be refused if either the patient is in too high an ASA risk class [37], or if the hospital and personnel are not adequately 
equipped to perform sedation to the required standard. The physician must then explain to the patient why sedation is not possible.

Whether patients should be informed of the possibility of dying as a result of the intervention is debated. In two judgments of the Regional Appeal Court Stuttgart, Germany $[207,208]$ and one of the Regional Appeal Court Zweibrücken, Germany [209] it was required that the patient be gently informed before colonoscopy of the possibility of dying as a result of perforation. In another case, it was required that the patient be informed that she could die as a consequence of an ERCP.

\subsubsection{Safety information (patient do's and don'ts after endoscopic sedation)}

Recommendation: Patients should be told about what it is safe for them to do or not to do after sedation and discharge from outpatient treatment, and should be given an information leaflet.

Recommendation grade A, evidence level 5 , strong consensus

Comments: Patients undergoing endoscopy as an outpatient procedure should be told that they need to bring someone who at least will accompany them home safely and also, if possible, keep them under observation for a few hours. In addition, all patients who are sedated must be told that they must not be out in road traffic, operate complicated machinery, drink alcohol, or make important or legally binding decisions. Patients should always be given a telephone number to contact the physician or hospital if they feel unwell or have bleeding after the endoscopy $[11,23,201]$. The patient should be given the information on do's and don'ts for the period after the examination in written form and in person [11,201,202]. For critical procedures or patients, a telephone call the next day is more effective than a written reminder [210].

\subsection{Requirements for carrying out sedation}

Recommendation: A permanent intravenous access is required for sedation.

Recommendation grade $\mathrm{A}$, evidence level $2 \mathrm{~b}$, strong consensus

Comment: Peripheral venous access is a fundamental requirement for the administration of sedatives.

A comparative study by Smith et al. [211] investigated the functionality of butterfly and indwelling catheters 1 hour after endoscopy, a time when most benzodiazepines and opiates have not even reached their half-life. Only $44 \%$ of the butterflies but $98 \%$ of the indwelling catheters were still functional.

\subsection{Protection of vital functions}

Recommendation: Sedated patients should receive oxygen prophylactically via a nasal tube.

Recommendation grade $\mathrm{A}$, evidence level $2 \mathrm{~b}$, strong consensus

Comment: Incidents due to sedation are usually cardiopulmonary events [203]. These make up about half of all complications in endoscopy, and depending on the patient's risk level can also occur during gastroscopy without sedation [212]. Earlier publications reported a $5 \%$ incidence of cardiopulmonary events with benzodiazepine use [124]. In more recent studies using propofol, the rate was between $0.0 \%$ and $0.65 \%$, and in a large observational study on colonoscopy screening in Germany it was $0.1 \%$. Eighty percent of the examinations in this study were done under seda- tion, but the drug was not specified [213]. Older patients in particular are at risk of hypoxia under sedation $[13,103]$.

Prophylactic oxygen administration via a nasal tube can significantly reduce the frequency of hypoxemic events [214-216]. However, there are also indications that prophylactic oxygen administration can delay the early detection of hypoxemic events using pulse oximetry [20].

\subsection{Management of sedation-related emergencies \\ 4.4.1 Hypoxemia}

Hypoxia is present if oxygen saturation declines below $90 \%$ as measured with a pulse oximeter. Most pulse oximeters indicate the level of oxygen saturation by the pitch of the impulse. Thus, if the tone frequency becomes lower or the digitally visible oxygen saturation drops continuously, counteractive measures must be taken. Initially this means asking patients in a loud voice and stimulating them by touch to breathe deeper. If the patients are on their back their chin can be pulled up using an Esmarch grip (so-called jaw-thrust maneuver), allowing them to breathe freely again through the mouth. Placement of a Güdel or a Wendel tube may be of help. In addition, the oxygen flow should be increased (e.g., from 2 to $4-5 \mathrm{~L} / \mathrm{min}$ ).

Should the patient not develop spontaneous breathing with these measures, ventilatory support must be continued. The airways should be secured instrumentally (e.g., intubation).

If the patient was sedated with benzodiazepines, in addition the antagonist flumazenil should immediately be given intravenously. This often makes ventilation unnecessary. Otherwise the procedure for hypoxia under benzodiazepines is the same as for propofol.

\subsubsection{Cardiac arrhythmias}

\subsubsection{General}

Endoscopic intubation of the colon is enough by itself to cause excessive activation of the sympathetic autoregulative nervous system in unsedated patients [217], thus increasing the probability of cardiovascular events. The influence on heart rate variability is enhanced further by sedation [218]. However, cardiopulmonary events can also be observed in unsedated patients during gastroscopy [140].

\subsubsection{Tachyarrhythmia}

There are no reports in the literature on tachycardia requiring intervention, only on frequent supraventricular and ventricular extrasystoles [219]. In emergencies, class Ia-IV antiarrhythmics should be given intravenously and a defibrillator should be kept at hand according to the guidelines of the cardiological professional associations [220].

\subsubsection{Bradyarrhythmia}

Occasionally bradycardia occurs, especially during colonoscopy with or without sedation. The incidence is reported at $0.5 \%$ [189]. However, drug intervention was only necessary in one third of the patients. The intervention consists of giving $0.5 \mathrm{mg}$ atropine intravenously, repeated if necessary up to a dose of $3 \mathrm{mg}$, and/or adrenaline $0.02-0.1 \mathrm{mg}$ intravenously. In lifethreatening situations resuscitation with heart massage should be done [220]. 


\subsubsection{Arterial hypotension}

The incidence of arterial hypotension during colonoscopy varies between $0.3 \%$ [189] and 3\%-19\% depending on the definition [217]. The intervention for arterial hypotension is an infusion of physiological saline solution. Prophylactic infusion in all colonoscopies is not recommended [221], but may well be a good choice in older dehydrated patients. Prophylactic intravenous administration of fluids can also be useful for long procedures carried out under propofol sedation, because of the pronounced bloodpressure-reducing properties of propofol.

\subsubsection{Myocardial ischemia}

Myocardial ischemia can occur during endoscopy with or without sedation. In a prospective study ST-segment depression was described in $7 \%$ of patients undergoing colonoscopy. Three-quarters of these events occurred before the actual endoscopy [222]. ST depression can be significantly reduced by oxygen supplementation during endoscopy [216]. There is one published report of a case of heart attack during colonoscopy [155].

\subsubsection{Rare events during sedation}

Allergies and local pain reactions (usually related to injections into small veins) are occasionally seen during endoscopy of sedated patients. In 80000 colonoscopies, one allergic reaction to midazolam was observed [205]. Allergic reactions to soy protein have been observed after propofol injection (see Section 2.2.1.1). The drugs required to manage allergic reactions (e.g., adrenaline, cortisone, antihistamines) should be readily available in the endoscopy unit.

\section{Quality goals: internal quality assurance/discharge criteria/fitness for road traffic/ability to work/docu- mentation/ benchmarking}

To achieve high-quality outcomes in a process, it is necessary to define and comply with quality goals.

Moderation of the process of development of quality measurement procedures follows a fixed structured course and starts with definition of the quality goals. Quality goals can relate to patient care or to the outcome of treatment. In the international literature an "indicator statement" is often given instead of a quality goal.

The first stage is completion of the half-sentence: "Good quality is when..."

- Patients are able to decide for themselves for or against sedation on the basis of an optimal patient information process.

- Patients undergoing gastrointestinal endoscopy receive appropriate sedation adapted to their individual needs and health.

- A high rate of patient acceptance for endoscopic examinations is reached, especially in screening programs.

- Endoscopists have optimal examination conditions because of the sedation.

- Patients have no complications because they are appropriately monitored during sedation, and patient safety is high because the incidence of sedation-related complications is minimized.

- If unforeseen complications occur, patients can be treated quickly and carefully according to the rules of medicine.

- Patients are adequately cared for until discharged.
Table 13 Minimum criteria for patient discharge after sedated endoscopy (according to [224]).

Walking without assistance

Completely (or largely) pain-free

Oral fluid intake without difficulty

No or only slight nausea

Sufficient care at home

If needed, repeat information on typical signs of complications from the physician, emergency telephone number to take home

Discharge with an accompanying person

- Patients are not discharged until any severe impairments caused by the drug that have not completely subsided are no longer detectable.

The abovelisted points are intended to contribute to optimization and compliance with the defined quality goals.

Since this is the first version of the S3 guideline on sedation for gastrointestinal endoscopy, and the data available on this topic are very limited, explicit indicators with reference ranges beyond the quality goals have not yet been defined.

To investigate whether the quality goals recommended here are already in effect, the guideline group decided that comprehensive data should be collected from practical experience in patient care. These results will be used to establish more specific quality indicators according to the BQS procedures [see, Federal Office for Quality Assurance (Bundesgeschäftsstelle für Qualitätssicherung)] as part of the updating process.

\subsection{Internal quality assurance}

Recommendation: There should be a written and easily comprehensible procedure plan for carrying out sedation, monitoring the patient after sedation, the criteria for discharge to the outpatient or general inpatient area, and the management of any complications. The respective responsibilities should be clearly defined. Recommendation grade A, evidence level 5, strong consensus

\subsection{Discharge criteria}

\subsubsection{Patient instructions}

Recommendation: Patients should have an accompanying person when they are discharged. They should also receive written instructions including a 24-hour emergency telephone number in case of complications.

Recommendation grade A, evidence level 5, strong consensus

\subsubsection{Minimum criteria for discharge}

Recommendation: The minimum criteria for discharge (according to the Report of the Working Party on Guidelines for Sedation by Non-Anesthetists [224]) should be met and documented.

Recommendation grade A, evidence level 5, strong consensus (० Table 13)

\subsubsection{Use of score systems for discharge}

Recommendation: Score systems (e.g., Aldrete score) should not be the sole basis for decisions as to whether patients can be discharged, because they do not evaluate psychomotor function.

Recommendation grade $B$, evidence level $2 \mathrm{~b}$, strong consensus

Comment: The use of a modified Aldrete score [225] allows statements only about patients' vital functions, but not about their psychomotor performance, which may be considerably impaired even when a maximum score is obtained [226]. 
Even if patients have stable vital signs and seem sufficiently awake after sedation, it is known that after the use of intermediate-acting substances (e.g., midazolam, pethidine) patients have a prolonged phase of amnesia and impairment of reflexes and judgment.

Patients undergoing colonoscopy who are sedated with frequently employed combination of midazolam plus opiate show impairments of reaction time, fine motor skills, and perception for at least 30 minutes after the procedure. Study data show that the remaining after-effects of midazolam impair various aspects of psychomotor function for at least 1 hour after administration $[226,227]$. Midazolam seems in these cases to be the main reason for the persistent impairment of psychomotor function after sedation [228]. A study by Thapar et al. [228] comparing the effect of midazolam with fentanyl and propofol gave similar results.

\subsection{Fitness for road traffic}

Recommendation: Whether a patient is fit for road traffic, whether as an active (i.e., driving) or a passive participant (i.e., using public transportation), should be decided at the time of discharge taking into account the half-life of the drug used and the individual patient's risk profile.

Recommendation grade A, evidence level 1b, strong consensus

Comment: The normalization of psychomotor function on the day of the examination is essentially dependent on the half-life of the substance used. Short-acting substances have an advantage in this respect.

A study by Riphaus et al. [8] of 98 patients compared sedation with propofol versus midazolam/pethidine for gastroscopy and colonoscopy. Compared to midazolam/pethidine, no impairment of psychomotor function (tested using a driving simulator) was seen 2 hours after sedation with propofol.

After the use of short-acting hypnotics (e.g., propofol), fitness to use the roads seems to be restored when the half-life is reached. Nonetheless, because the number of patients in this study was small, the most that is considered possible is the use of public transport (including without an accompanying person). Much larger field studies are necessary for decisions about riding a bicycle or driving a car.

The currently valid recommendation of the various professional associations [9-11] to neither drive a vehicle nor use public transport for 24 hours seems too strict considering that there is no evidence to support the choice of this time period, especially in relation to the ultra-short-acting substances such as propofol and remifentanil.

A whole series of studies by Korttila et al. [229-231] dating back to the 1970s investigated psychomotor function after sedation with various drugs. These showed that even when benzodiazepines were used at higher doses (diazepam $0.45 \mathrm{mg} / \mathrm{kg}$ b.w.), psychomotor functions were restored after 10 hours [230]. Only when pethidine $75 \mathrm{mg}$ i.m. was used were psychomotor functions impaired for up to 12 hours, and in this case the recommendation not to drive for 24 hours seems justifiable - but pethidine $75 \mathrm{mg}$ i.m. is no longer routinely used in endoscopy [229].

\subsection{Documentation}

Recommendation: The patient file or the documentation form should contain time-dependent documentation of the vital signs (oxygen saturation, heart rate, and blood pressure), the drugs used including name and dose, the administration of intravenous fluids, and whether and at what flow rate the patient received oxy- gen. Ideally, the degree of sedation grade and patient's statements about pain experienced should also be periodically documented. Recommendation grade A, evidence level 5, strong consensus

\subsubsection{General}

Documentation is an essential part of patient care and should be done in all phases of the intervention.

These include:

- Preintervention evaluation of the patient

- Giving the patient all relevant information about the intervention

- Monitoring during the intervention

- Patient recovery

- Patient discharge

Ideally, a standardized documentation form should be used, because this improves documentation compliance [232].

\subsubsection{Inability to work}

Recommendation: The time for which a person is unfit for work is judged on an individual basis taking account of the nature of the workplace, the duration and depth of sedation, and the drug used. Recommendation grade 0 , evidence level 5 , consensus

Comment: A general recommendation cannot be given on how long a patient is unfit for work after the use of sedatives and analgesics for gastrointestinal endoscopy. The usual recommendation of 24 hours after sedation can be viewed as too long when short-acting drugs have been used.

\subsection{Benchmarking}

Recommendation: All complications (drop in oxygen saturation, hypotension, mask ventilation, intubation, and death) that occur during endoscopy with or without sedation should be documented.

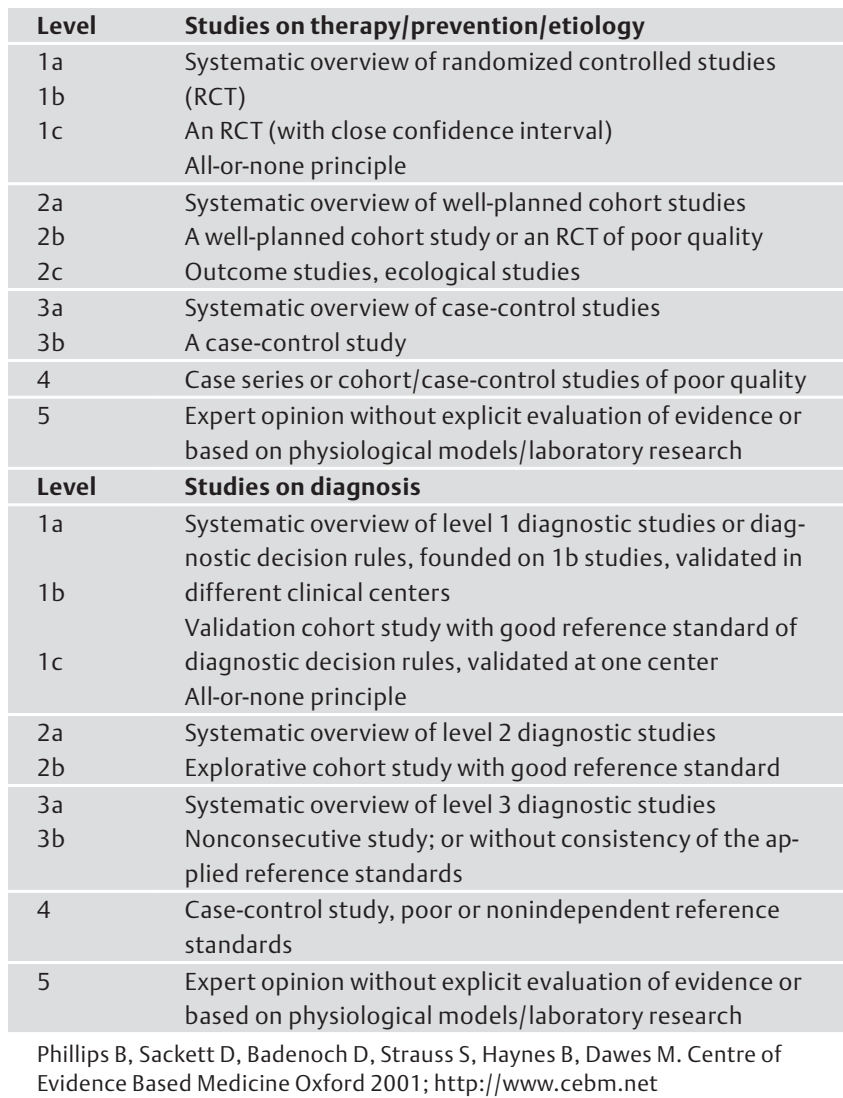


Recommendation grade 0 , evidence level 5 , consensus

Comments: A "benchmark" in the transferred sense means competitive comparison of the orientation parameter (characteristic) or all comparative parameters for relative evaluation of a product, service, or organization unit. The most important benchmark for sedation during gastrointestinal endoscopy should be a complication rate that is as low as possible.

A nationwide survey of all endoscopic examinations and associated complications with and without sedation is desirable.

The abovementioned complications should be centrally recorded and evaluated, so that subsequently procedures can be optimized.

\section{Appendix 1}

$\nabla$

Methodological quality of scientific supporting documents: classification of evidence level according to the Oxford Centre for Evidence Based Medicine, 2001.

\section{Appendix 2}

From evidence to recommendation: classification of the recommendation grade

Recommendations are graded according to: Bundesärztekammer, AWMF, Kassenärztliche Bundesvereinigung, eds. Programm für Nationale Versorgungsleitlinien - Methodenreport. Berlin: ÄZQ www.methodik.n-v-l.de. ( Fig. 1).

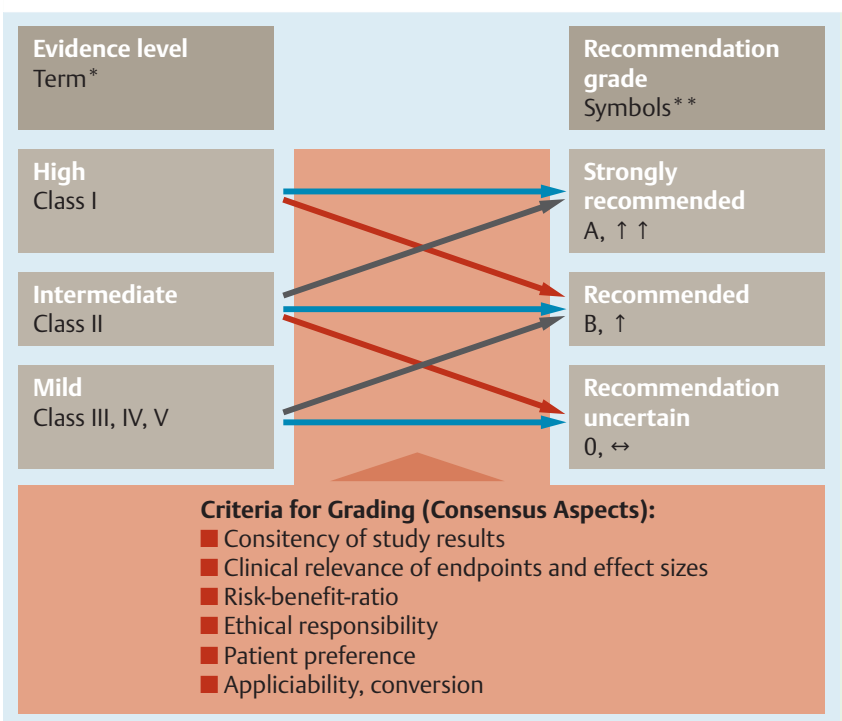

Fig. 1 Kopp I, Lelgemann M, Ollenschläeger G. EbM und Leitlinien. In: Kunz R et al, eds. Lehrbuch Evidenzbasierte Medizin in Klinik und Praxis. 2nd edn. Cologne: Deutscher Ärzteverlag; 2007:374

${ }^{*}$ According to the GRADE working group (BMJ 2004; 328:1490) and the Oxford Centre of Evidence Based Medicine (www.cebm.net/levels_of_evidence.asp).

* * Symbols for recommendation grade in the Program for National Health Care Guidelines ( www.methodik.n-v-l.de and http://www.leitlinienmanual. de). So far as possible, the recommendations are stated in similar terms: Strong recommendation: "must"; recommendation: "should"; recommendation open: "may" (optional action). Negative recommendations are expressed verbally ("not") with the same symbols.
Competing interests: Competing interests of the authors are listed below. All authors state that their competing interest does not lead to a potential conflict of interest in respect of their participation in the guideline process.

A. Riphaus: Speaker's fees: Fresenius Kabi Germany, Nycomed Germany, Falk Foundation Germany, Astra Zeneca, Germany. Research support: Fresenius Kabi Germany, Oridion Germany

T. Wehrmann: Speaker's fees: Fresenius Kabi Germany, Nycomed Germany, Falk Foundation Germany, Astra Zeneca, Germany. Research support: Fresenius Kabi Germany, Oridion Germany

B. Weber: Speaker's fees: Fresenius Kabi Germany

J. Arnold: Speaker's fees: Falk Foundation Germany, Roche Pharma, Gilead, Olympus Hamburg Germany, Danone Netherland

U. Beilenhoff: None

H. Bitter: None

S. von Delius: Speaker's fees: ESAI Pharma. Research support: Karl Storz GmbH \& Co. KG, Tuttlingen, Germany; Pulsion Medical Systems, Munich, Germany; Olympus, Hamburg, Germany; Erbe Elektromedizin, Tübingen, Germany; Danmeter A/S, Odense, Denmark; Aspect Medical Systems, Newton, Mass., USA

\section{Domagk: None}

A. F. Ehlers: None

S. Faiss: Speaker's fees: Falk Foundation Germany, Nycomed Germany

D. Hartmann: None

W. Heinrichs: Owner of AQAI company, which provides training for safe sedation in gastroenterology. Support from Fresenius Kabi, Germany; Ferring, Germany

M.-L. Hermans: None

C. Hofmann: None

S. In der Smitten: None

M. Jung: None

G. Kähler: Research support: Medi-Globe GmbH, Achenmühle, Germany; Erbe Elektromedizin Deutschland Tübingen, Germany; Karl-Storz Endoskopie Tuttlingen, Germany; Serag Wiessner KG, Naila, Germany; Olympus Deutschland GmbH, Germany M. Kraus: None

J. Martin: Speaker's fees: Glaxo SmithKline, Fresenius Kabi Germany, B. Braun, Germany

A. Meining: None

J. Radke: None

T. Rösch: None

H. Seifert: Speaker's fees: Falk Foundation Germany, Roche Pharma, Essex Pharma

A. Sieg: None

B. Wigginghaus: None

I. Kopp: None

\section{References}

1 Daneshmend TK, Bell GD, Logan RF. Sedation for upper gastrointestinal endoscopy: results of a nationwide survey. Gut 1991; 32: $12-15$

2 Keefe EB, O'Connor KW. ASGE survey of endoscopic sedation and monitoring practices. Gastrointest Endosc 1990; 36: 13 - 18

3 Froehlich F, Gonvers JJ, Fried M. Conscious sedation, clinically relevant complications and monitoring of endoscopy: results of a nationwide survey in Switzerland. Endoscopy 1994; 26: 231 - 234

4 Frühmorgen P, Kriel L. Guidelines of the German Society of Digestive and Metabolic Diseases. Guidelines for endoscopic colorectal polypectomy with the sling. German Society of Digestive and Metabolic Diseases. Gastroenterol 1998; 36: $117-119$

5 Riphaus A, Rabofski M, Wehrmann T. Sedierung in der gastrointestinalen Endoskopie in Deutschland. Z Gastroenterol 2007; 45: 782 
6 Carlsson U, Grattidge P. Sedation for upper gastrointestinal endoscopy: a comparative study of propofol and midazolam. Endoscopy 1995; 27: $240-243$

7 Patterson KW, Casey PB, Murray JP et al. Propofol sedation for outpatient upper gastrointestinal endoscopy: comparison with midazolam. Br J Anaesth 1991; 67: 108 - 111

8 Riphaus A, Gstettenbauer T, Frenz MB, Wehrmann T. Quality of psychomotor recovery after propofol sedation for routine endoscopy: a randomized and controlled study. Endoscopy 2006; 38: 677-683

9 Clinical practice guidelines: safety and sedation during endoscopic procedures.Available from: http://www.bsg.org.uk/pdf_word_docs/ sedation.doc

10 Stufe 1 Leitlinie Sedierung und Analgesie (Analgosedierung) von Patienten durch Nicht-Anästhesisten. 2008.Available from: http://www. dgai.de/06pdf/13_573-Leitlinie.pdf, http://intranet/awmf11/001-011. htm

11 Hofmann C, Jung $M$. Sedierung und Überwachung bei endoskopischen Eingriffen. 2003.Available from: http://www.dgvs.de/media/1.2.Sedierung-ueberwachung.pdf

12 Kulling $D$, Rothenbuhler $R$, Inauen $W$. Safety of nonanesthetist sedation with propofol for outpatient colonoscopy and esophagogastroduodenoscopy. Endoscopy 2003; 35: 679-682

13 Heuss LT, Drewe J, Schnieper P et al. Patient-controlled versus nurse-administered sedation with propofol during colonoscopy. A prospective randomized trial. Am J Gastroenterol 2004; 99: 511 - 518

14 Heuss LT, Schnieper P, Drewe J et al. Risk stratification and safe administration of propofol by registered nurses supervised by the gastroenterologist: a prospective observational study of more than 2000 cases. Gastrointest Endosc 2003; 57: 664-671

15 Rex DK, Heuss LT, Walker JA, Qi R. Trained registered nurses/endoscopy teams can administer propofol safely for endoscopy. Gastroenterology 2005; $129: 1384-1391$

16 Rex DK, Overley C, Kinser K et al. Safety of propofol administered by registered nurses with gastroenterologist supervision in 2000 endoscopic cases. Am J Gastroenterol 2002; 97: 1159-1163

17 Walker JA, McIntyre RD, Schleinitz PF et al. Nurse-administered propofol sedation without anesthesia specialists in 9152 endoscopic cases in an ambulatory surgery center. Am J Gastroenterol 2003; 98: 1744 1750

18 Tohda G, Higashi S, Wakahara S et al. Propofol sedation during endoscopic procedures: safe and effective administration by registered nurses supervised by endoscopists. Endoscopy 2006; 38: 360 - 367

19 American Society of Anesthesiologists Task Force. Practice guidelines for sedation and analgesis by non-anesthesiologists: an updated report by the American Society of Anestesiologists Task Force on Sedation and Analgesia by Non-Anesthesiologists. Anesthesiology 2002; 96: 1004 1017

20 American Society for Gastrointestinal Endoscopy. Guidelines for conscious sedation and monitoring during gastrointestinal endoscopy. Gastrointest Endosc 2003; 58: 317-322

21 American Society of Anesthesiologists. Practice guidelines for postanesthetic care: a report by the American Society of Anesthesiologists Task Force on Postanesthetic Care. Anesthesiology 2002; 6: 742 - 752

22 Joint statement of a Working Group from the American College of Gastroenterology (ACG), the American Gastroenterological Association (AGA), and the American Society for Gastrointestinal Endoscopy (ASGE). Recommendations on the administration of sedation for the performance of endoscopic procedures. 2006.Available from: www.gi. org/physicians/nataffairs/trisociety.asp

23 Schreiber F. Austrian Society of Gastroenterology and Hepatology (OGGH) - guidelines on sedation and monitoring during gastrointestinal endoscopy. Endoscopy 2007; 39: 259-262

24 American Society for Gastrointestinal Endoscopy. Guidelines for training in patient monitoring and sedation and analgesia. Gastrointest Endosc 1998; 48: 669-671

25 Waring JP, Baron TH, Hirota WK et al. Guidelines for conscious sedation and monitoring during gastrointestinal endoscopy. Gastrointest Endosc 2003; 58: 317-322

26 Probert CS, Jayanthi V, Quinn J, Mayberry JF. Information requirements and sedation preferences of patients undergoing endoscopy of the upper gastrointestinal tract. Endoscopy 1991; 23: 218-219

27 Rex DK, Imperiale TF, Portish V. Patients willing to try colonoscopy without sedation: associated clinical factors and results of a randomized controlled trial. Gastrointest Endosc 1999; 49: 554-559
28 Eckardt VF, Kanzler G, Schmitt T et al. Complications and adverse effects of colonoscopy with selective sedation. Gastrointest Endosc 1999; 49: $560-565$

29 Yoruk G, Aksoz K, Unsal B et al. Colonoscopy without sedation. Turk J Gastroenterol 2003; 14: 59-63

30 Early DS, Saifuddin T, Johnson JC et al. Patient attitudes toward undergoing colonoscopy without sedation. Am J Gastroenterol 1999; 94: $1862-1865$

31 Cohen LB, Wecsler JS, Gaetano JN et al. Endoscopic sedation in the United States: results from a nationwide survey. Am J Gastroenterol 2006; 101: 967-974

32 Thompson DG, Lennard-Jones JE, Evans SJ et al. Patients appreciate premedication for endoscopy. Lancet 1980; 2: 469-470

33 Dillon M, Brown S, Casey Wet al. Colonoscopy under general anesthesia in children. Pediatrics 1998; 102: 381 - 383

34 Ely EW, Truman B, Shintani A et al. Monitoring sedation status over time in ICU patients: reliability and validity of the Richmond Agitation-Sedation Score (RASS). JAMA 2003; 289: 2983-2991

35 Cohen $L B$, Delegge $M H$, Aisenberg J et al. AGA Institute review of endoscopic sedation. Gastroenterology 2007; 133: 675-701

36 Dripps RD, Lamont A, Eckenhoff JE. The role of anesthesia in surgical mortality. JAMA 1961; 178: 261-266

37 American Society of Anesthesiologists. Practice guidelines for sedation and analgesia by non-anesthesiologists. A report by the American Society of Anesthesiologists Task Force on Sedation and Analgesia by Non-Anesthesiologists. Anesthesiology 1996; 84: 459-471

38 Society of Gastroenterology Nurses and Associates. SGNA position statement: Statement on the use of sedation and analgesia in the gastrointestinal endoscopy setting. Gastroenterol Nurs 2003; 26: 209-211

39 Society of Gastroenterology Nurses and Associates. SGNA position statement. Statement on the use of sedation and analgesia in the gastrointestinal endoscopy setting. Gastroenterol Nurs 2004; 27: 142 - 144

40 Faigel DO, Baron TH, Goldstein JL et al. Guidelines for the use of deep sedation and anesthesia for GI endoscopy. Gastrointest Endosc 2002; 56: 613-617

41 American Society for Gastrointestinal Endoscopy. Sedation and monitoring of patients undergoing gastrointestinal endoscopic procedures. Gastrointest Endosc 1995; 42: 626-629

42 Deutsche Gesellschaft für Anästhesiologie und Intensivmedizin. Leitlinie der Deutschen Gesellschaft für Anästhesiologie und Intensivmedizin. Airway management. Anästh Intensivmed 2004; 45: 302 - 306

43 Koch DG, Arguedas MR, Fallon MB. Risk of aspiration pneumonia in suspected variceal hemorrhage: the value of prophylactic endotracheal intubation prior to endoscopy. Dig Dis Sci 2007; 52: 2225 - 2228

44 Rudolph SJ, Landsverk BK, Freeman ML. Endotracheal intubation for airway protection during endoscopy for severe upper GI hemorrhage. Gastrointest Endosc 2003; 57: 58-61

45 Deutsche Gesellschaft für Anästhesiologie und Intensivmedizin. Vereinbarung des Berufsverbandes Deutscher Anästhesisten und des Berufverbandes der Deutschen Chirurgen. Verantwortung für die prä-, intra- und postoperative Lagerung des Patienten. Anästh Intensivmed 1987: $28: 65$

46 Olithselvan A, McIntyre AS, Gorard DA. Are patients' sedation preferences at gastroscopy influenced by preceding patients' decisions? Aliment Pharmacol Ther 2004; 20: 989-992

47 Campo R, Brullet E, Montserrat A et al. Identification of factors that influence tolerance of upper gastrointestinal endoscopy. Eur J Gastroenterol Hepatol 1999; 11: $201-204$

48 Subramanian S, Liangpunsakul S, Rex DK. Preprocedure patient values regarding sedation for colonoscopy. J Clin Gastroenterol 2005; 39: $516-519$

49 Abraham NS, Fallone CA, Mayrand S et al. Sedation versus no sedation in the performance of diagnostic upper gastrointestinal endoscopy: a Canadian randomized controlled cost-outcome study. Am J Gastroenterol 2004; 99: 1692 - 1699

50 Hedenbro JL, Ekelund M, Aberg T, Lindblom A. Oral sedation for diagnostic upper endoscopy. Endoscopy 1991; 23: 8-10

51 Kinoshita $Y$, Ishido S, Nishiyama $\mathrm{K}$ et al. Arterial oxygen saturation, blood pressure, and pulse rate during upper gastrointestinal endoscopy - influence of sedation and age. J Clin Gastroenterol 1991; 13: 656660

52 Yuno $K$, Iishi $H$, Tatsuta $M$ et al. Intravenous midazolam as a sedative for colonoscopy: a randomized, double-blind clinical trial. Aliment Pharmacol Ther 1996; 10: 981 - 984 
53 Marriott P, Laasch HU, Wilbraham L et al. Conscious sedation for endoscopic and non-endoscopic interventional gastrointestinal procedures: meeting patients' expectations, missing the standard. Clin Radiol 2004; 59: 180-185

54 Ristikankare M, Hartikainen J, Heikkinen $M$ et al. Is routinely given conscious sedation of benefit during colonoscopy? Gastrointest Endosc 1999; 49: 566 - 572

55 Walmsley RS, Montgomery SM. Factors affecting patient tolerance of upper gastrointestinal endoscopy. J Clin Gastroenterol 1998; 26: $253-255$

56 Roseveare C, Seavell C, Patel P et al. Patient-controlled sedation and analgesia, using propofol and alfentanil, during colonoscopy: a prospective randomized controlled trial. Endoscopy 1998; 30: 768 - 773

57 Ulmer BJ, Hansen JJ, Overley CA et al. Propofol versus midazolam/fentanyl for outpatient colonoscopy: administration by nurses supervised by endoscopists. Clin Gastroenterol Hepatol 2003; 1: 425 - 432

58 Vargo JJ, Zuccaro G Jr., Dumot JA et al. Gastroenterologist-administered propofol versus meperidine and midazolam for advanced upper endoscopy: a prospective, randomized trial. Gastroenterology 2002; 123: $8-16$

59 Sipe BW, Rex DK, Latinovich D et al. Propofol versus midazolam/meperidine for outpatient colonoscopy: administration by nurses supervised by endoscopists. Gastrointest Endosc 2002; 55: 815 - 825

60 Weston BR, Chadalawada V, Chalasani $N$ et al. Nurse-administered propofol versus midazolam and meperidine for upper endoscopy in cirrhotic patients. Am J Gastroenterol 2003; 98: 2440 - 2447

61 Mui LM, Teoh AY, Ng EK et al. Premedication with orally administered midazolam in adults undergoing diagnostic upper endoscopy: a double-blind placebo-controlled randomized trial. Gastrointest Endosc 2005; 61: $195-200$

62 von Delius S, Hollweck R, Schmid RM, Frimberger E. Midazolam - pain, but one cannot remember it: a survey among Southern German endoscopists. Eur J Gastroenterol Hepatol 2007; 19: 465 - 470

63 Laluna L, Allen ML, Dimarino AJ Jr.. The comparison of midazolam and topical lidocaine spray versus the combination of midazolam, meperidine, and topical lidocaine spray to sedate patients for upper endoscopy. Gastrointest Endosc 2001; 53: 289 - 293

$64 \mathrm{Ng} J M$, Kong CF, Nyam D. Patient-controlled sedation with propofol for colonoscopy. Gastrointest Endosc 2001; 54: 8-13

65 Patel S, Vargo IJ, Khandwala F et al. Deep sedation occurs frequently during elective endoscopy with meperidine and midazolam. Am J Gastroenterol 2005; 100: 2689-2695

66 Jung M, Hofmann C, Kiesslich R, Brackertz A. Improved sedation in diagnostic and therapeutic ERCP: propofol is an alternative to midazolam. Endoscopy 2000; 32: 233 - 238

67 Wehrmann T, Kokabpick S, Caspary WF et al. Efficiacy and safety of intravenous profol sedation during routine ERCP. Gastrointest Endosc 1999; 49: 677-683

68 Hofmann C, Kiesslich R, Brackertz A, Jung M. Propofol for sedation in gastroscopy - a randomized comparison with midazolam [in German]. Z Gastroenterol 1999; 37: 589 - 595

69 Koshy G, Nair S, Norkus EP et al. Propofol versus midazolam and meperidine for conscious sedation in GI endoscopy. Am J Gastroenterol 2000; 95: 1476 - 1479

70 Reimann FM, Samson U, Derad I et al. Synergistic sedation with lowdose midazolam and propofol for colonoscopies. Endoscopy 2000; 32: $239-244$

71 Heuss LT, Schnieper P, Drewe J et al. Conscious sedation with propofol in elderly patients: a prospective evaluation. Aliment Pharmacol Ther 2003; 17: $1493-1501$

72 Kazama T, Takeuchi K, Ikeda K et al. Optimal propofol plasma concentration during upper gastrointestinal endoscopy in young, middleaged, and elderly patients. Anesthesiology 2000; 93: 662-669

73 Rex DK, Overley CA, Walker J. Registered nurse-administered propofol sedation for upper endoscopy and colonoscopy: Why? When? How? Rev Gastroenterol Disord 2003: 3: 70-80

74 Gottschling $S$, Larsen $R$, Meyer $S$ et al. Acute pancreatitis induced by short-term propofol administration. Paediatr Anaesth 2005; 15: $1006-1008$

75 Jawaid Q, Presti ME, Neuschwander-Tetri BA, Burton FR. Acute pancreatitis after single-dose exposure to propofol: a case report and review of literature. Dig Dis Sci 2002; 47: 614-618

76 Fodale $V$, La Monaca E. Propofol infusion syndrome: an overview of a perplexing disease. Drug Saf 2008; 31: 293 - 303
77 Kulling D, Fantin AC, Biro P et al. Safer colonoscopy with patient-controlled analgesia and sedation with propofol and alfentanil. Gastrointest Endosc 2001; 54: 1 - 7

78 Bright E, Roseveare C, Dalgleish D et al. Patient-controlled sedation for colonoscopy: a randomized trial comparing patient-controlled administration of propofol and alfentanil with physician-administered midazolam and pethidine. Endoscopy 2003; 35: 683-687

79 Lee DW, Chan AC, Sze TS et al. Patient-controlled sedation versus intravenous sedation for colonoscopy in elderly patients: a prospective randomized controlled trial. Gastrointest Endosc 2002; 56: 629-632

80 Crepeau T, Poincloux L, Bonny C et al. Significance of patient-controlled sedation during colonoscopy. Results from a prospective randomized controlled study. Gastroenterol Clin Biol 2005; 29: 1090 - 1096

81 Lee DW, Chan AC, Wong SK, Chung SC. The safety, feasibility, and acceptability of patient-controlled sedation for colonoscopy: prospective study. Hong Kong Med J 2004; 10: $84-88$

82 Egan TD, Kern SE, Johnson KB, Pace NL. The pharmacokinetics and pharmacodynamics of propofol in a modified cyclodextrin formulation (Captisol) versus propofol in a lipid formulation (Diprivan): an electroencephalographic and hemodynamic study in a porcine model. Anesth Analg 2003; 97: 72 - 79

83 Fanti L, Agostoni M, Arcidiacono PG et al. Target-controlled infusion during monitored anesthesia care in patients undergoing EUS: propofol alone versus midazolam plus propofol. A prospective double-blind randomised controlled trial. Dig Liver Dis 2007; 39: 81 - 86

84 Leslie K, Absalom A, Kenny GN. Closed loop control of sedation for colonoscopy using the bispectral index. Anaesthesia 2002; 57: 693-697

85 Campbell L, Imrie G, Doherty P et al. Patient maintained sedation for colonoscopy using a target controlled infusion of propofol. Anaesthesia 2004; 59: $127-132$

86 Gillham MJ, Hutchinson RC, Carter R, Kenny GN. Patient-maintained sedation for ERCP with a target-controlled infusion of propofol: a pilot study. Gastrointest Endosc 2001; 54: 14-17

87 Stonell CA, Leslie K, Absalom AR. Effect-site targeted patient-controlled sedation with propofol: comparison with anaesthetist administration for colonoscopy. Anaesthesia 2006; 61: 240-247

88 Pambianco J, Meroric J, Martin R. Feasibility assessment of computer assisted personalized sedation: a sedation delivery system to administer propofol for gastrointestinal endoscopy. Gastrointest Endosc 2006; 63: AB189

89 Reves JG, Fragen RJ, Vinik HR, Greenblatt DJ. Midazolam: pharmacology and uses. Anesthesiology 1985; 62: $310-324$

90 Donnelly MB, Scott WA, Daly DS. Sedation for upper gastrointestinal endoscopy: a comparison of alfentanil-midazolam and meperidine-diazepam. Can J Anaesth 1994; 41: 1161 -1165

91 Ginsberg GG, Lewis JH, Gallagher JE et al. Diazepam versus midazolam for colonoscopy: a prospective evaluation of predicted versus actual dosing requirements. Gastrointest Endosc 1992; 38: 651 - 656

92 Macken E, Gevers AM, Hendrickx A, Rutgeerts P. Midazolam versus diazepam in lipid emulsion as conscious sedation for colonoscopy with or without reversal of sedation with flumazenil. Gastrointest Endosc 1998; 47: $57-61$

93 Lavies NG, Creasy T, Harris K, Hanning CD. Arterial oxygen saturation during upper gastrointestinal endoscopy: influence of sedation and operator experience. Am J Gastroenterol 1988; 83: 618-622

94 Carrougher JG, Kadakia S, Shaffer RT, Barrilleaux C. Venous complications of midazolam versus diazepam. Gastrointest Endosc 1993; 39: $396-399$

95 Ladas SD, Aabakken L, Rey JF et al. Use of sedation for routine diagnostic upper gastrointestinal endoscopy: a European Society of Gastrointestinal Endoscopy Survey of National Endoscopy Society Members. Digestion 2006; 74: 69-77

96 Zakko SF, Seifert HA, Gross JB. A comparison of midazolam and diazepam for conscious sedation during colonoscopy in a prospective double-blind study. Gastrointest Endosc 1999; 49: 684-689

97 Cantor DS, Baldridge ET. Premedication with meperidine and diazepam for upper gastrointestinal endoscopy precludes the need for topical anesthesia. Gastrointest Endosc 1986; 32: 339- 341

98 Lee MG, Hanna W, Harding $H$. Sedation for upper gastrointestinal endoscopy: a comparative study of midazolam and diazepam. Gastrointest Endosc 1989; 35: $82-84$

99 Lader M, Morton S. Benzodiazepine problems. Br J Addict 1991; 86: $823-828$

100 Christe C, Janssens JP, Armenian B et al. Midazolam sedation for upper gastrointestinal endoscopy in older persons: a randomized, double- 
blind, placebo-controlled study. J Am Geriatr Soc 2000; 48: 1398 1403

101 Froehlich F, Schwizer W, Thorens J et al. Conscious sedation for gastroscopy: patient tolerance and cardiorespiratory parameters. Gastroenterology 1995; 108: 697-704

102 Froehlich F, Thorens J, Schwizer W et al. Sedation and analgesia for colonoscopy: patient tolerance, pain, and cardiorespiratory parameters. Gastrointest Endosc 1997; 45: 1 -9

103 Yano $H$, Iishi $H$, Tatsuta $M$ et al. Oxygen desaturation during sedation for colonoscopy in elderly patients. Hepatogastroenterology 1998; 45: $2138-2141$

104 Hirsh I, Vaissler A, Chernin J et al. Fentanyl or tramadol, with midazolam, for outpatient colonoscopy: analgesia, sedation, and safety. Dig Dis Sci 2006; 51: $1946-1951$

105 Lee SY, Son HJ, Lee JM et al. Identification of factors that influence conscious sedation in gastrointestinal endoscopy. J Korean Med Sci 2004; 19: $536-540$

106 Morrow JB, Zuccaro G Jr., Conwell DL et al. Sedation for colonoscopy using a single bolus is safe, effective, and efficient: a prospective, randomized, double-blind trial. Am J Gastroenterol 2000; 95: 2242 2247

107 Terruzzi V, Meucci G, Radaelli F et al. Routine versus "on demand" sedation and analgesia for colonoscopy: a prospective randomized controlled trial. Gastrointest Endosc 2001; 54: 169-174

108 Kankaria A, Lewis JH, Ginsberg G et al. Flumazenil reversal of psychomotor impairment due to midazolam or diazepam for conscious sedation for upper endoscopy. Gastrointest Endosc 1996; 44: 416-421

109 Saletin M, Malchow $H$, Muhlhofer $H$ et al. A randomised controlled trial to evaluate the effects of flumazenil after midazolam premedication in outpatients undergoing colonoscopy. Endoscopy 1991; 23: $331-333$

110 Mora CT, Torjman M, White PF. Sedative and ventilatory effects of midazolam infusion: effect of flumazenil reversal. Can J Anaesth 1995; 42: 677-684

111 Carter AS, Bell GD, Coady T et al. Speed of reversal of midazolam-induced respiratory depression by flumazenil - a study in patients undergoing upper GI endoscopy. Acta Anaesthesiol Scand Suppl 1990; 92: 59-64

112 Andrews PJ, Wright DJ, Lamont MC. Flumazenil in the outpatient. A study following midazolam as sedation for upper gastrointestinal endoscopy. Anaesthesia 1990; 45: 445-448

113 Bartelsman JF, Sars PR, Tytgat GN. Flumazenil used for reversal of midazolam-induced sedation in endoscopy outpatients. Gastrointest Endosc 1990; 36: 9-12

114 Norton AC, Dundas CR. Induction agents for day-case anaesthesia. A double-blind comparison of propofol and midazolam antagonised by flumazenil. Anaesthesia 1990; 45: 198-203

115 Wehrmann T, Grotkamp J, Stergiou $N$ et al. Electroencephalogram monitoring facilitates sedation with propofol for routine ERCP: a randomized, controlled trial. Gastrointest Endosc 2002; 56: 817-824

116 Meining A, Semmler V, Kassem AM et al. The effect of sedation on the quality of upper gastrointestinal endoscopy: an investigator-blinded, randomized study comparing propofol with midazolam. Endoscopy 2007; 39: $345-349$

117 Hansen JJ, Ulmer BJ, Rex DK. Technical performance of colonoscopy in patients sedated with nurse-administered propofol. Am J Gastroenterol 2004; 99: $52-56$

118 Rudner R, Jalowiecki P, Kawecki P et al. Conscious analgesia/sedation with remifentanil and propofol versus total intravenous anesthesia with fentanyl, midazolam, and propofol for outpatient colonoscopy. Gastrointest Endosc 2003; 57: 657-663

119 Qadeer MA, Vargo JJ, Khandwala F et al. Propofol versus traditional sedative agents for gastrointestinal endoscopy: a meta-analysis. Clin Gastroenterol Hepatol 2005; 3: 1049-1056

120 Krugliak P, Ziff B, Rusabrov Y et al. Propofol versus midazolam for conscious sedation guided by processed EEG during endoscopic retrograde cholangiopancreatography: a prospective, randomized, double-blind study. Endoscopy 2000; 32: 677-682

121 Riphaus A, Stergiou N, Wehrmann T. Sedation with propofol for routine ERCP in high-risk octogenarians: a randomized, controlled study. Am J Gastroenterol 2005; 100: 1957-1963

122 Wehrmann T, Riphaus A. Sedation with propofol for interventional endoscopic procedures: a risk factor analysis. Scand J Gastroenterol 2007; 10: $1-7$
123 Ishiguro T, Ishiguro C, Ishiguro G, Nagawa H. Midazolam sedation for upper gastrointestinal endoscopy: comparison between the states of patients in partial and complete amnesia. Hepatogastroenterology 2002; 49: $438-440$

124 Arrowsmith JB, Gerstman BB, Fleischer DE, Benjamin SB. Results from the American Society for Gastrointestinal Endoscopy/US Food and Drug Administration collaborative study on complication rates and drug use during gastrointestinal endoscopy. Gastrointest Endosc 1991; 37: 421 - 427

125 Basu S, Krishnamurthy B, Walsh TH. Value of fentanyl in flexible sigmoidoscopy. World J Surg 2004; 28: 930-934

126 Ishido S, Kinoshita Y, Kitajima $N$ et al. Fentanyl for sedation during upper gastrointestinal endoscopy. Gastrointest Endosc 1992; 38: 689 692

127 Akcaboy ZN, Akcaboy EY, Albayrak D et al. Can remifentanil be a better choice than propofol for colonoscopy during monitored anesthesia care? Acta Anaesthesiol Scand 2006; 50: 736 - 741

128 Green SM, Li J. Ketamine in adults: what emergency physicians need to know about patient selection and emergence reactions. Acad Emerg Med 2000; 7: 278-281

129 White PF, Way WL, Trevor AJ. Ketamine - its pharmacology and therapeutic uses. Anesthesiology 1982; 56: 119-136

130 Aggarwal A, Ganguly S, Anand VK, Patwari AK. Efficacy and safety of intravenous ketamine for sedation and analgesia during pediatric endoscopic procedures. Indian Pediatr 1998; 35: 1211 - 1214

131 Gilger MA, Spearman RS, Dietrich CL et al. Safety and effectiveness of ketamine as a sedative agent for pediatric GI endoscopy. Gastrointest Endosc 2004; 59: 659-663

132 Rosing C, Trinkl W, Rosing K, Gebhardt B. Midazolam plus ketamine as premedication for colonoscopies. A double-blind, randomized study [in German]. Med Klin (Munich) 1991; 86: 190-193

133 Ong WC, Santosh D, Lakhtakia S, Reddy DN. A randomized controlled trial on use of propofol alone versus propofol with midazolam, ketamine, and pentazocine "sedato-analgesic cocktail" for sedation during ERCP. Endoscopy 2007; 39: 807-812

134 Saunders BP, Fukumoto M, Halligan S et al. Patient-administered nitrous oxide/oxygen inhalation provides effective sedation and analgesia for colonoscopy. Gastrointest Endosc 1994; 40: 418-421

135 Forbes GM, Collins BJ. Nitrous oxide for colonoscopy: a randomized controlled study. Gastrointest Endosc 2000; 51: 271 - 277

136 Maslekar SK, Hughes M, Skinn E et al. Randomised controlled trial of sedation for colonoscopy: entonox versus intravenous sedation. Gastrointest Endosc 2006; 63: AB 97S

137 Mui WL, Kwong WH, Li AC et al. Premedication with intravenous ketorolac trometamol (Toradol) in colonoscopy: a randomized controlled trial. Am J Gastroenterol 2005; 100: 2669-2673

138 Lieberman DA, Wuerker CK, Katon RM. Cardiopulmonary risk of esophagogastroduodenoscopy. Role of endoscope diameter and systemic sedation. Gastroenterology 1985; 88: 468-472

139 Mizuno J, Matsuki M, Gouda Y et al. Sedation with intravenous midazolam during upper gastrointestinal endoscopy - changes in hemodynamics, oxygen saturation and memory [in Japanes]. Masui 2003; 52: $976-980$

140 Oei-Lim VL, Kalkman CJ, Makkes PC, Ooms WG. Patient-controlled versus anesthesiologist-controlled conscious sedation with propofol for dental treatment in anxious patients. Anesth Analg 1998; 86: $967-$ 972

141 Ristikankare $M$, Julkunen $R$, Heikkinen $M$ et al. Sedation, topical pharyngeal anesthesia and cardiorespiratory safety during gastroscopy. J Clin Gastroenterol 2006; 40: 899-905

142 Boldy DA, Lever LR, Unwin PR et al. Sedation for endoscopy: midazolam or diazepam and pethidine? Br J Anaesth 1988; 61: 698-701

143 Milligan KR, Howe JP, McLoughlin J et al. Midazolam sedation for outpatient fibreoptic endoscopy: evaluation of alfentanil supplementation. Ann R Coll Surg Engl 1988; 70: 304-306

144 Radaelli F, Meucci G, Terruzzi V et al. Single bolus of midazolam versus bolus midazolam plus meperidine for colonoscopy: a prospective, randomized, double-blind trial. Gastrointest Endosc 2003; 57: 329 335

145 Paspatis GA, Manolaraki M, Xirouchakis G et al. Synergistic sedation with midazolam and propofol versus midazolam and pethidine in colonoscopies: a prospective, randomized study. Am J Gastroenterol 2002; 97: $1963-1967$

146 Seifert H, Schmitt TH, Gultekin T et al. Sedation with propofol plus midazolam versus propofol alone for interventional endoscopic pro- 
cedures: a prospective, randomized study. Aliment Pharmacol Ther 2000; 14: $1207-1214$

147 DiPalma JA, Herrera JL, Weis FR et al. Alfentanil for conscious sedation during colonoscopy. South Med J 1995; 88: 630-634

148 Moerman AT, Struys MM, Vereecke HE et al. Remifentanil used to supplement propofol does not improve quality of sedation during spontaneous respiration. J Clin Anesth 2004; 16: 237 - 243

149 Rembacken BJ, Axon AT. The role of pethidine in sedation for colonoscopy. Endoscopy 1995; 27: 244-247

150 VanNatta ME, Rex DK. Propofol alone titrated to deep sedation versus propofol in combination with opioids and/or benzodiazepines and titrated to moderate sedation for colonoscopy. Am J Gastroenterol 2006; 101: 2209-2217

151 Cordruwisch W, Doroschko M, Wurbs D. Deep sedation in gastrointestinal endoscopic interventions: safety and reliability of a combination of midazolam and propofol [in German]. Dtsch Med Wochenschr 2000; 125: 619-622

152 Mui LM, Ng EK, Chan KC et al. Randomized, double-blinded, placebocontrolled trial of intravenously administered hyoscine N-butyl bromide in patients undergoing colonoscopy with patient-controlled sedation. Gastrointest Endosc 2004; 59: 22 - 27

153 Vargo JJ, Holub JL, Faigel DO et al. Risk factors for cardiopulmonary events during propofol-mediated upper endoscopy and colonoscopy. Aliment Pharmacol Ther 2006; 24: 955 - 963

154 Iber FL, Sutberry M, Gupta R, Kruss D. Evaluation of complications during and after conscious sedation for endoscopy using pulse oximetry. Gastrointest Endosc 1993; 39: 620-625

155 Thompson AM, Park KG, Kerr F, Munro A. Safety of fibreoptic endoscopy: analysis of cardiorespiratory events. Br J Surg 1992; 79: 10461049

156 Assy N, Rosser BG, Grahame GR, Minuk GY. Risk of sedation for upper GI endoscopy exacerbating subclinical hepatic encephalopathy in patients with cirrhosis. Gastrointest Endosc 1999; 49: 690-694

157 Vasudevan AE, Goh KL, Bulgiba AM. Impairment of psychomotor responses after conscious sedation in cirrhotic patients undergoing therapeutic upper GI endoscopy. Am J Gastroenterol 2002; 97: $1717-1721$

158 Muravchick S. Anesthesia for the geriatric patient. In: Barash PG, Cullen BF, Stoelting RK, eds. Clinical anesthesia. 4th edn. Philadelphia: Lippincott-Raven, 2001: 1205-1216

159 Qureshi WA, Zuckerman MJ, Adler DG et al. ASGE guideline: modifications in endoscopic practice for the elderly. Gastrointest Endosc 2006; 63: $566-569$

160 Darling E. Practical considerations in sedating the elderly. Crit Care Nurs Clin North Am 1997; 9: 371 - 380

161 Dhariwal A, Plevris JN, Lo NT et al. Age, anemia, and obesity-associated oxygen desaturation during upper gastrointestinal endoscopy. Gastrointest Endosc 1992; 38: 684-688

162 Scholer SG, Schafer DF, Potter JF. The effect of age on the relative potency of midazolam and diazepam for sedation in upper gastrointestinal endoscopy. J Clin Gastroenterol 1990; 12: 145 - 147

163 Hamdy NA, Kennedy HJ, Nicholl J, Triger DR. Sedation for gastroscopy: a comparative study of midazolam and Diazemuls in patients with and without cirrhosis. Br J Clin Pharmacol 1986; 22: 643-647

164 Riphaus A, Lechowicz I, Frenz MB et al. Profol sedation for upper GI endoscopy in patients with liver cirrhosis as alternative to avoid acute deterioration of minimal encephalopathy. A randomized controlled study. Scand J Gastroenterol 2009 in press

165 Heuss LT, Schnieper P, Drewe J et al. Safety of propofol for conscious sedation during endoscopic procedures in high-risk patients - a prospective, controlled study. Am J Gastroenterol 2003; 98: 1751 - 1757

166 Harikumar R, Raj M, Paul A et al. Listening to music decreases need for sedative medication during colonoscopy: a randomized, controlled trial. Indian J Gastroenterol 2006; 25: 3-5

167 Rudin D, Kiss A, Wetz RV, Sottile VM. Music in the endoscopy suite: a meta-analysis of randomized controlled studies. Endoscopy 2007; 39: $507-510$

168 Aisenberg J, Cohen LB. Sedation in endoscopic practice. Gastrointest Endosc Clin N Am 2006; 16: 695-708

169 American Medical Association. The use of pulse oximetry during conscious sedation. Council on Scientific Affairs. JAMA 1993; 270: 1463 1468

170 Conigliaro R, Rossi A. Implementation of sedation guidelines in clinical practice in Italy: results of a prospective longitudinal multicenter study. Endoscopy 2006; 38: 1137-1143
171 Eisenbacher S, Heard L. Capnography in the gastroenterology lab. Gastroenterol Nurs 2005; 28: $99-105$

172 Graber RG. Propofol in the endoscopy suite: an anesthesiologist's perspective. Gastrointest Endosc 1999; 49: 803 - 806

173 Harris JK, Froehlich F, Wietlisbach $V$ et al. Factors associated with the technical performance of colonoscopy: An EPAGE Study. Dig Liver Dis 2007; 39: 678-689

174 Jamieson J. Anesthesia and sedation in the endoscopy suite? (influences and options). Curr Opin Anaesthesiol 1999; 12: 417-423

175 Kulling D, Orlandi M, Inauen W. Propofol sedation during endoscopic procedures: how much staff and monitoring are necessary? Gastrointest Endosc 2007; 66: 443 - 449

176 Leslie K, Stonell CA. Anaesthesia and sedation for gastrointestinal endoscopy. Curr Opin Anaesthesiol 2005; 18: 431 - 436

177 Lopez RL Subcomite de Protocolos of The Spanish Society of Gastrointestinal Endoscopy (SEED). Sedation/analgesia guidelines for endoscopy. Rev Esp Enferm Dig 2006; 98: 685 - 692

178 Mahoney LB, Lightdale JR. Sedation of the pediatric and adolescent patient for GI procedures. Curr Treat Options Gastroenterol 2007; 10: 412-421

179 Moos DD, Cuddeford JD. Methemoglobinemia and benzocaine. Gastroenterol Nurs 2007; 30: $342-345$

180 Morlote EB, Zweng TN, Strodel WE. Hemodynamic monitoring and pulse oximetry during percutaneous gastrostomy and jejunostomy: necessity or nuisance? Surg Endosc 1991; 5: 130-134

181 Overley $C A, \operatorname{Rex} D K$. A nursing perspective on sedation and nurse-administered propofol for endoscopy. Gastrointest Endosc Clin N Am 2004; 14: $325-333$

182 Robbertze R, Posner KL, Domino KB. Closed claims review of anesthesia for procedures outside the operating room. Curr Opin Anaesthesiol 2006; 19: $436-442$

183 Society of Gastroenterology Nurses and Associates. Guidelines for nursing care of the patient receiving sedation and analgesia in the gastrointestinal endoscopy setting. Gastroenterol Nurs 1997; 20 (Suppl): $1-6$

184 American Society for Gastrointestinal Endoscopy. Training guideline for use of propofol in gastrointestinal endoscopy. Gastrointest Endosc 2004; 60: $167-172$

185 Vargo JJ, Ahmad AS, Aslanian HR et al. Training in patient monitoring and sedation and analgesia. Gastrointest Endosc 2007; 66: 7 - 10

186 Zebris J, Maurer W. Quality assurance in the endoscopy suite: sedation and monitoring. Gastrointest Endosc Clin N Am 2004; 14: 415 429

187 Silvermann W, Chotiprasidhi R, Chuttani J et al. Monitoring equipment for endoscopy. Gastrointest Endosc 2003; 59: 761 - 765

188 Kiesslich R, Moenk S, Reinhardt K et al. Combined simulation training a new concept and workshop is useful for crisis management in gastrointestinal endoscopy [in German]. Z Gastroenterol 2005; 43 : 1031 - 1039

189 Sieg A. Propofol sedation in outpatient colonoscopy by trained practice nurses supervised by the gastroenterologist: a prospective evaluation of over 3000 cases. Z Gastroenterol 2007; 45: 697-701

190 Heuss LT, Froehlich F, Beglinger C. Changing patterns of sedation and monitoring practice during endoscopy: results of a nationwide survey in Switzerland. Endoscopy 2005; 37: 161-166

191 Froehlich F, Harris JK, Wietlisbach V et al. Current sedation and monitoring practice for colonoscopy: an International Observational Study (EPAGE). Endoscopy 2006; 38: 461 - 469

192 Anderson JL, Junkins E, Pribble C, Guenther E. Capnography and depth of sedation during propofol sedation in children. Ann Emerg Med 2007; 49: 9-13

193 Levine DA, Platt SL. Novel monitoring techniques for use with procedural sedation. Curr Opin Pediatr 2005; 17: 351 - 354

194 Soto RG, Fu ES, Vila H Jr., Miguel RV. Capnography accurately detects apnea during monitored anesthesia care. Anesth Analg 2004; 99: $379-382$

195 Vargo JJ, Zuccaro G Jr., Dumot JA et al. Automated graphic assessment of respiratory activity is superior to pulse oximetry and visual assessment for the detection of early respiratory depression during therapeutic upper endoscopy. Gastrointest Endosc 2002; 55: 826-831

196 Koniaris LG, Wilson S, Drugas G, Simmons W. Capnographic monitoring of ventilatory status during moderate (conscious) sedation. Surg Endosc 2003; 17: $1261-1265$ 
197 Chen SC, Rex DK. An initial investigation of bispectral monitoring as an adjunct to nurse-administered propofol sedation for colonoscopy. Am J Gastroenterol 2004; 99: 1081 - 1086

198 Drake LM, Chen SC, Rex DK. Efficacy of bispectral monitoring as an adjunct to nurse-administered propofol sedation for colonoscopy: a randomized controlled trial. Am J Gastroenterol 2006; 101: 2003 2007

199 Parzreller $M$, Wenk $M$. Aufklärung und Einwilligung bei ärztlichen Eingriffen. Dtsch Ärztebl 2007; 109: A576-A586

200 Christopher J. Gastrointestinal bleeding in the elderly patient. Am J Gastroenterol 2000; 95: 590-595

201 Hochberger J. Die Einverständniserklärung zu endoskopischen Eingriffen. In: Sauerbruch T, Scheurlen C, eds. Empfehlungen der Deutschen Gesellschaft für Verdauungs- und Stoffwechselkrankheiten (DGVS) zur Durchführung endoskopischer Untersuchungen. 3rd edn. Stuttgart: Demeter, 2002: 1 - 11

202 Rieger HJ. Zur Rechtzeitigkeit der Patientenaufklärung. Dtsch Med Wochschr 2003; 28: 1728-1729

203 Sieg A, Hachmoeller-Eisenbach U, Eisenbach T. Prospective evaluation of complications in outpatient GI endoscopy: a survey among German gastroenterologists. Gastrointest Endosc 2001; 53: 620-627

204 Mahajan RJ, Johnson JC, Marshall JB. Predictors of patient cooperation during gastrointestinal endoscopy. J Clin Gastroenterol 1997; 24: 220-223

205 Pena LR, Mardini HE, Nickl NJ. Development of an instrument to assess and predict satisfaction and poor tolerance among patients undergoing endoscopic procedures. Dig Dis Sci 2005; 50: 1860 - 1871

206 Lazzaroni M, Bianchi PG. Preparation, premedication, and surveillance. Endoscopy 2005; 37: 101 - 109

207 Laufs A, Uhlenbruck W. Handbuch des Arztrechts. 3rd edn. 2002

208 Oberlandesgericht Stuttgart MedR41 - 42. 1986

209 Oberlandesgericht Zweibrücken MedR407-408. 1995

210 Hayes A, Buffum M. Educating patients after conscious sedation for gastrointestinal procedures. Gastroenterol Nurs 2001; 24: 54-57

211 Smith MR, Bell GD, Fulton B et al. A comparison of winged steel needles and Teflon cannulas in maintaining intravenous access during gastrointestinal endoscopy. Gastrointest Endosc 1993; 39: 33-36

212 Alcain G, Guillen P, Escolar A et al. Predictive factors of oxygen desaturation during upper gastrointestinal endoscopy in nonsedated patients. Gastrointest Endosc 1998; 48: 143-147

213 Sieg A, Theilmeier A. Results of coloscopy screening in 2005 - an Internet-based documentation [in German]. Dtsch Med Wochenschr 2006; $131: 379-383$

214 Jurell KR, O'Connor KW, Slack J et al. Effect of supplemental oxygen on cardiopulmonary changes during gastrointestinal endoscopy. Gastrointest Endosc 1994; 40: 665-670

215 Reshef R, Shiller M, Kinberg R et al. A prospective study evaluating the usefulness of continuous supplemental oxygen in various endoscopic procedures. Isr J Med Sci 1996; 32: 736 - 740
216 Wang CY, Ling LC, Cardosa MS et al. Hypoxia during upper gastrointestinal endoscopy with and without sedation and the effect of pre-oxygenation on oxygen saturation. Anaesthesia 2000; 55: 654-658

217 Ristikankare M, Julkunen R, Mattila $M$ et al. Conscious sedation and cardiorespiratory safety during colonoscopy. Gastrointest Endosc 2000; $52: 48-54$

218 Petelenz M, Gonciarz M, Macfarlane P et al. Sympathovagal balance fluctuates during colonoscopy. Endoscopy 2004; 36: 508 - 514

219 Bhalla A, Sood A, Sachdeva A et al. Cardiorespiratory compromise under conscious sedation during upper gastrointestinal endoscopy. J Coll Physicians Surg Pak 2006; 16: 585 - 589

220 Lewalter T. Notfall Herzrhythmusstörungen. Dtsch Ärztebl 2007; 104: A1172-A1180

221 Leslie K, Tay T, Neo E. Intravenous fluid to prevent hypotension in patients undergoing elective colonoscopy. Anaesth Intensive Care 2006; 34: $316-321$

222 Ristikankare M, Julkunen R, Laitinen $T$ et al. Effect of conscious sedation on cardiac autonomic regulation during colonoscopy. Scand J Gastroenterol 2000; 35: 990 - 996

223 Sieg A, Hachmoeller-Eisenbach U, Heisenbach T. How safe is premedication in ambulatory endoscopy in Germany? A prospective study in gastroenterology specialty practices [in German]. Dtsch Med Wochenschr 2000; 125: 1288 - 1293

224 Royal College of Surgeons of England Commission on the Provision of Surgical Services. Report of the working party on guidelines for sedation by non-anesthetists. 1993. www.rcseng.ac.uk/fds/clinical_guidelines-31k

225 Aldrete JA. The post-anesthesia recovery score revisited. J Clin Anesth 1995; 7: 89-91

226 Willey J, Vargo JJ, Connor JT et al. Quantitative assessment of psychomotor recovery after sedation and analgesia for outpatient EGD. Gastrointest Endosc 2002; 56: 810-816

227 Nuotto EJ, Korttila KT, Lichtor JL et al. Sedation and recovery of psychomotor function after intravenous administration of various doses of midazolam and diazepam. Anesth Analg 1992; 74: 265 - 271

228 Thapar P, Zacny JP, Thompson W, Apfelbaum JL. Using alcohol as a standard to assess the degree of impairment induced by sedative and analgesic drugs used in ambulatory surgery. Anesthesiology 1995; 82: $53-59$

229 Korttila K, Linnoila M. Psychomotor skills related to driving after intramuscular administration of diazepam and meperidine. Anesthesiology 1975; 125: 619-622

230 Korttila K, Linnoila M. Recovery and skills related to driving after intravenous sedation: dose-response relationship with diazepam. $\mathrm{Br}$ Anaesth 1975; 47: 457-463

231 Korttila K. Recovery after intravenous sedation. A comparison of clinical and paper and pencil tests used in assessing late effects of diazepam. Anaesthesia 1976; 31: 724-731

232 Piletti R, Davis PJ, Redlinger $R$ et al. Effect on hospital wide sedation practice after implentation of the 2001 JCAHO procedural sedation and analgesia guidelines. Arch Adolesc Med 2006; 160: 211 -216 